\title{
Spam Works: Evidence from Stock Touts and Corresponding Market Activity
}

\section{Citation}

Laura Frieder and Jonathan Zittrain, Spam Works: Evidence from Stock Touts and Corresponding Market Activity, Berkman Center Research Publication No. 2006-11(2007), 13 Hastings Communications and Entertainment Law Journal 479 (2008).

\section{Published Version}

http://cyber.law.harvard.edu/sites/cyber.law.harvard.edu/files/Spam\%20Works.pdf; http:// heinonline.org.ezp-prod1.hul.harvard.edu/HOL/Page?collection=journals\&handle=hein.journals/ hascom30\&id $=497$

\section{Permanent link}

http://nrs.harvard.edu/urn-3:HUL.InstRepos:4455162

\section{Terms of Use}

This article was downloaded from Harvard University's DASH repository, and is made available under the terms and conditions applicable to Other Posted Material, as set forth at http:// nrs.harvard.edu/urn-3:HUL.InstRepos:dash.current.terms-of-use\#LAA

\section{Share Your Story}

The Harvard community has made this article openly available.

Please share how this access benefits you. Submit a story.

Accessibility 
March 31, 2007

\title{
Spam Works: Evidence from Stock Touts and Corresponding Market Activity
}

\author{
Laura L. Frieder* \\ Jonathan Zittrain**
}

*Assistant Professor of Finance, Krannert School of Management, Purdue University, 425 West State Street, West Lafayette, IN 47907; phone: 765494 4462; e-mail: lilfrieds@purdue.edu.

** Professor of Internet Governance and Regulation, Oxford University, 1 St Giles, Oxford, OX1 3JS, United Kingdom; phone: 617495 4643; e-mail: z@oii.ox.ac.uk.

We appreciate the valuable suggestions of Alana Black, Rainer Böhme, Mike Cooper, David Denis, Mila Getmansky, Austan Goolsbee, Guido Imbens, Camelia Kuhnen, Laura Lindsey, Sandy Klasa, Jennifer Juergens, Antonio Macias, John McConnell, Terry Odean, Ed Schlee, John Reed Stark, Avanidhar Subrahmanyam, Hongfei Tang, Heather Tookes, and Rebecca Zarutskie, and the excellent research assistance of David Buchwald, Ravi Chandra, Bryan Choi, Charles Duan, Antonio Macias, and Sally Walkerman. Thanks also to Yim Cheung, R. Cromwell Coulson, Mike Dorsey, and Carl Giangrasso from Pink Sheets, LLC, for valuable information and providing the data. 


\section{Abstract \\ Spam Works: Evidence from Stock Touts and Corresponding Market Activity}

We assess the impact of spam that touts stocks upon the trading activity of those stocks and sketch how profitable such spamming might be for spammers and how harmful it is to those who heed advice in stock-touting e-mails. We find convincing evidence that stock prices are being manipulated through spam. We suggest that the effectiveness of spammed stock touting calls into question prevailing models of securities regulation that rely principally on the proper labeling of information and disclosure of conflicts of interest as means of protecting consumers, and we propose several regulatory and industry interventions.

Based on a large sample of touted stocks listed on the Pink Sheets quotation system and a large sample of spam emails touting stocks, we find that stocks experience a significantly positive return on days prior to heavy touting via spam. Volume of trading responds positively and significantly to heavy touting. For a stock that is touted at some point during our sample period, the probability of it being the most actively traded stock in our sample jumps from $4 \%$ on a day when there is no touting activity to $70 \%$ on a day when there is touting activity. Returns in the days following touting are significantly negative. The evidence accords with a hypothesis that spammers "buy low and spam high," purchasing penny stocks with comparatively low liquidity, then touting them perhaps immediately after an independently occurring upward tick in price, or after having caused the uptick themselves by engaging in preparatory purchasing - in order to increase or maintain trading activity and price enough to unload their positions at a profit. We find that prolific spamming greatly affects the trading volume of a targeted stock, drumming up buyers to prevent the spammer's initial selling from depressing the stock's price. Subsequent selling by the spammer (or others) while this buying pressure subsides results in negative returns following touting. Before brokerage fees, the average investor who buys a stock on the day it is most heavily touted and sells it 2 days after the touting ends will lose close to $5.5 \%$. For those touted stocks with above-average levels of touting, a spammer who buys on the day before unleashing touts and sells on the day his or her touting is the heaviest, on average, will earn $4.29 \%$ before transaction costs.

For access to our raw data and interactive charts showing price and volume changes for individual touted and control stocks, see:

$$
<\text { http://cyber.law.harvard.edu/stockspam }>
$$




\section{Introduction}

Unsolicited e-mail is said to account for over $80 \%$ of all Internet e-mail traffic, with estimates topping 1.6 billion messages per week. $15 \%$ of these are stock touts. ${ }^{1}$ Stocktouting spam asks a user to invest in a specific stock, and often concedes in its fine print that the spammer has a financial interest in touting those stocks. When they invest in a stock in which the spammer (or the spammer's client) holds a stake, spam recipients can maintain or drive up the price during the spammer's selling so that the stock can be liquidated at a profit. For example, in a well-known case brought by the U.S. Securities and Exchange Commission, it was found that stock touter Jonathan Lebed routinely purchased stock accounting for anywhere from $17 \%$ to $46 \%$ of the stock's market volume for a day, and sent spammed e-mail touts on the same day. He then lodged limit orders to sell for the next day's trading session, anticipating a rise in the stock price after the general public received his touts and some recipients acted on them (In Re Lebed (2000)). (Lebed's case and subsequent settlement with the S.E.C. focused on his failure to disclose his own financial interest in the securities he touted; as discussed below, stock touts today often include such disclosures).

We match price and volume data from Pink Sheets, LLC to ticker symbols that appear in e-mail touts received by one of the authors and by the moderated Internet Usenet newsgroup news.admin.net-abuse.sightings (NANAS) between January of 2004 and July of 2005, and compare the presence and volume of spam that touts particular stocks with the price and volume behavior of those stocks before, during, and after the touts. The stocks in our sample tend to be touted over several days, and we find that, on average, there is a significant increase in stock price from the day before touting begins to the day with the most active touting. Volume also responds positively and significantly to heavy touting. Returns in the days following touting are significantly negative.

\footnotetext{
${ }^{1}$ See <http://www.postini.com/stats $>$. See also Sophos Security Threat Management Report (2006), available at <http://www.sophos.com/sophos/docs/eng/papers/sophos-security-report-jun06srus.pdf>, and <http://www.junk-o-meter.com/stats/index.php>.
} 
The touted stocks in our sample are nearly always found listed on the Pink Sheets market, and sometimes additionally on the Over the Counter Bulletin Board market (OTCBB). They are not listed on any major exchange, nor are they traded in large total dollar amounts, making them amenable to manipulation. Any mispricing that is created by trading in response to touting may persist since liquidity risk in these stocks is high which, in the absence of a tout-created market, may partially preclude arbitrage. Though we have no way of directly knowing if the spammer actually has holdings in the spammed stock apart from the spammer's own admission, when it appears, and our surmise that some pecuniary motive inspires sending the spam, the evidence accords with a hypothesis that spammers tout stocks in order to increase trading activity and price enough to unload their positions at a profit. Selling pressure on the part of the spammer then results in negative returns following heavy touting. These results are consistent with the model of Hong and Huang (2005) that suggests that, in highly illiquid markets (like Pink Sheets), traders with significant liquidity needs have an incentive to take costly actions that increase liquidity and decrease the impact of their trades.

Spam is comparatively cheap to send. Since 2002, relationships between spammers and virus authors have caused millions of virus-infected personal computers to be harnessed as "zombies" to send spam, ${ }^{2}$ further lowering its cost. In addition, unlike most other commercial spam, stock touts do not call for any direct (and therefore traceable) Internet-mediated reply from the person spammed, such as the sending of money to purchase a "spamvertised" product. Stock-touting spammers are therefore particularly difficult to identify and punish by private anti-spam consortia or public authorities reducing even more the cost of sending such spam. However, stock touts do call for action by their recipients, in the form of purchases placed in financial markets. If the volume of such purchases is high enough, it ought to be reflected in the price and/or volume information recorded for that market. Stock touting spam thus provides a unique way to measure how effective spam can be.

\footnotetext{
${ }^{2}$ For a discussion of this, see $<$ http://news.bbc.co.uk/2/hi/technology/3107613.stm $>$ and $<$ http://news.bbc.co.uk/2/hi/technology/2987558.stm>.
} 
A connection between touting and short-term price movements or volume suggests inefficiency in some parts of the securities market, with trading taking place not on the basis of underlying fundamentals, but rather thanks to misconceptions by some of those spammed with touts - people who not only read their spam and believe its contents, but who then undertake the effort to issue instructions to a broker to purchase the touted stock. In addition, the fact that Pink Sheets stocks are so inexpensive per share may attract amateur investors to this market. We find that the monetary value of the affected transactions that take place on Pink Sheets is generally small compared to that on the major exchanges - or to other notable methods of market manipulation. This makes a case for regulatory prioritization more difficult, even as touting is a phenomenon that may affect the most vulnerable of investors. Given the growth in the number of inexperienced individuals in the market, the potential for abuse is significant even as the dollar value in a given cycle of spamming is less than $\$ 100,000$.

The successes of spam touting that we document do, however, raise questions about the right scope and depth of government-sponsored consumer protection in an era in which the Internet has enabled both the ready reception of stock touts and corresponding one-click investing by amateurs who previously would have had brokers or other intermediaries to temper actions arising from their susceptibility to scams. Many of the stock-touting e-mails that we examine contain disclosures that the spammer would sell his or her own shares contemporaneously with the spam campaign, perhaps as a result of a campaign by the U.S. Securities and Exchange Commission in 2000 to crack down on stock touting by those who failed to disclose their own holdings in the touted stocks. ${ }^{3}$ Regulatory regimes that rely only on disclosure of information to investors who will then rationally weigh it may prove ineffective when the investors in question are so clearly disregarding what disclosures might be present.

Finally, successful spam touting calls into question the very notion that spam is

\footnotetext{
${ }^{3}$ The SEC campaign is described in Walker and Levine (2001), of which the Lebed case described in the Introduction is a part.
} 
in fact unwanted by the recipient. Recipients may wish to avoid spam generally, but at least some part of the Internet public appears to be hungry for investing advice and information, enough so to absorb and follow advice that is flatly against interest and delivered in one of the most reviled formats of the information age. In this, our results are consistent with Merton (1987) who, based on the observation that individual and institutional investors each hold just a small proportion of the universe of traded equities, assumes that investors only invest in those securities with which they are familiar. Indeed, touting a stock via spam is a mechanism by which a spammer can make a potential investor aware of a previously unheard-of company. Given that most firms listed on Pink Sheets are unknown to most investors, Merton's recognition hypothesis lends itself well to the notion behind touting in order to draw attention to an obscure stock. Our method cannot directly expose investor intent or behavior. Instead, we show that markets move in response to spamming efforts, suggesting that enough people fail to filter spam, and then read it, and then act upon it, to make spamming worthwhile. Evidence that touting stocks by spam "works" under the right circumstances helps to complete the puzzle of why spam is so voluminous.

The paper proceeds as follows. The data and method are reviewed in Section 2.

Results are presented in Section 3. In Sections 4 and 5, we provide a discussion and consider policy implications. Section 6 concludes.

\section{Literature Review, Data, and Method}

\subsection{Literature Review}

Previous literature has covered investor response to new information. For example, studying earnings surprises, Lee (1992) finds that individual investors tend to buy stock in reaction to the release of news, whether the news is positive or negative. This suggests that small investors may place more weight on the mere presence of news than on its information content. Barber and Odean (2005) find that individual investors 
buy significantly after "attention-drawing" events, such as a news release about a given company or a day that a stock experiences an extreme abnormal return. The stocks that they purchase often subsequently underperform those that they sell. Antweiler and Frank (2004) study the market response to messages posted on Yahoo! Finance and Raging Bull message boards about Dow Jones Industrial Average companies. They show that, besides predicting increased trading, significant postings about a stock are followed by statistically significant negative returns. This result suggests that many individuals who act on news (at least that posted on message boards) are trading at a disadvantage, if not outright irrationally. Cooper, Dimitrov, and Rau (2001) build upon this, showing that, by reacting to "information" that is not relevant to a firm's risk or fundamental value (in particular, purchasing shares of a stock that added ".com" to its name during the Internet boom), investors cause predictable patterns in volume and returns. Benabou and Laroque (1992) show that some insiders and others with privileged information can manipulate markets through distorted announcements because it can be difficult to determine whether such announcements are true, and because investors are especially attuned to announcements from seemingly credible sources.

While this literature examines response of investors to news and information that they seek to obtain, in this paper we examine their response to news that broader audiences passively receive, news of apparently no substantive validity. Here we look at stock touting that much less purports or appears to come from a credible source, and that is sent through a channel - e-mail spam - that is not a typical means for corporate communication of financial data. For market manipulation generally, Aggarwal and Wu (2003) create a model of market manipulation not specific to any particular means and find that manipulated stocks are less liquid and smaller than non-manipulated stocks, and are often listed in markets like OTCBB and Pink Sheets.

Concurrent working papers by Böhme \& Holz (2006) and Hanke and Hauser (2006) analyze the relationship between spammed stock touts and market movements. We compare our results and methods to theirs below. Additionally, some Internet users have 
tracked the performance of the stocks for which they received spam touts to see what happens to the value of the stock in the period around spamming. ${ }^{4}$

\subsection{Spam Data}

To perform our analysis, we extracted stock-touting spam messages from a large quantity of unsorted spam. Our initial data set consisted of a database of 1,802,016 spam messages culled from two sources: 26,273 messages were from the collected spam of one of this paper's authors, and 1,775,743 were retrieved from the Internet usenet newsgroup news.admin.net-abuse.sightings (NANAS). ${ }^{5}$ We first automatically extracted messages that appeared to be stock touts. This was done by selecting messages that met two conditions: (1) the message contained the word "stock," and (2) the message contained a ticker symbol-like word. Ticker symbol-like words were defined as sequences of four uppercase letters that were not common English words or abbreviations. ${ }^{6}$ This procedure identified 75,415 messages containing 28,803 different symbol-like words and dated between August 22, 2000, and August 2, 2005. The messages scanned were plain text rather than graphical image spam, which has become prevalent since 2005, presumably to foil spam filters attempting to scan text.

\footnotetext{
${ }^{4}$ See, for example, Joshua Cyr's <http://www.spamstocktracker.com>, Leonard Richardson's $<$ http://www.crummy.com/features/StockSpam $>$, or $<$ http://www.thetruthasiseeit.com $>$ by A. D. Freduenheim.

${ }^{5}$ NANAS is used for the purpose of alerting network administrators to spam in progress so that they might take action against it, and its archives contain time-stamped reports of spam from Internet users around the world. Reports to NANAS may result in actions taken against the spam. If such actions reduce the amount of identical spam in a batch reaching other recipients, it could reduce the effectiveness of stock-touting spam, making our results understated in comparison to spam that eludes NANAS reporting. While other stock spam may therefore have a larger market impact, the impact of NANAS may be limited, since spammed stock touts appear to be intended for immediate consumption against which subsequent filtering is ineffective. There is no way to assure that NANAS's archive is a representative cross-section of spam from around the world, but its contributors are found worldwide, and judgments can be made within the NANAS group between stocks touted very little, garnering few spam reports, or stocks touted heavily enough that multiple reports of the spam are found from different reporters.

${ }^{6}$ In practice, excluding English words and abbreviations was useful, as those words dominated the data when not excluded, and fewer than $3 \%$ of ticker symbol names on Pink Sheets are English words or abbreviations.
} 
Next we identified which of these 75,415 messages were actual touts and what stocks were being touted. Because the automated process was prone to false positives, many of the messages identified were not actual touts, and many messages touting only one stock contained several symbol-like words, we processed messages by hand. In the author's spam, we found that only 10 of all the spammed tickers were listed on NYSE, AMEX, or NASDAQ, and the bulk of tickers we analyzed were not so listed. We therefore chose to exclude these from our analysis and focused on stocks in less liquid markets. Thus, we composed a list of ticker symbols of all companies listed on the Pink Sheets and OTCBB markets (4,741 and 3,388 securities, respectively), and we considered only messages containing those symbols.

Rather than look at each message individually, we grouped messages by date of receipt and symbol. ${ }^{7}$ We hand processed 7,347 groups of messages, and found that 3,813 groups were actual touts. Because price data was not available for all the stocks we identified, our final list was reduced to 3,669 symbol-date groups. Of these 3,669 symboldate pairs, we found over 500 distinct stocks that were touted, all of which were listed on Pink Sheets, and at least 186 were also listed on OTCBB. Most were touted infrequently: 373 were touted fewer than ten different days (of which, 141 were touted only once); only 15 stocks were touted 30 or more different days. The number of messages in each symboldate grouping is also relevant, as touts that were distributed more widely were likely to make multiple appearances in our database. For the vast majority of symbol-date pairs, few messages were received: out of the 3,813 pairs, fewer than ten messages were received for 3,049 pairs (and for 1,489 of these, only one message was received). Yet, a substantial number were touted heavily: for 95 pairs, fifty or more messages were received. ${ }^{8}$

\footnotetext{
${ }^{7}$ For example, all messages containing the symbol "CWTD" received on February 13, 2004 were placed into a group, and representative messages were sampled to see if the presence of the symbol reflected an actual tout. Many messages contained more than one symbol, and so those messages were placed into multiple groups accordingly.

${ }^{8}$ Böhme \& Holz (2006) and Hanke and Hauser (2006) perform similar studies. These studies also face the task of developing an archive of stock touting spam. Both draw upon a database of spam e-mails compiled by Leonard Richardson, who runs a web site that automates the process of comparing a given stock spam to that stock's performance on the day of receipt (see ¡http://www.crummy.com/features/StockSpam/reports/i). Richardson describes his stock spam as a
} 


\subsection{Stock Data}

We also gathered trading data about the spammed stocks in our sample. All but a handful of the touted stocks are traded on Pink Sheets, LLC. Pink Sheets is a principal provider of trading information for over-the-counter stocks and bonds not listed with major exchanges or NASDAQ. Unlike markets for other over-the-counter stocks (e.g., OTCBB, which is operated and regulated by the National Association of Securities Dealers (NASD)), Pink Sheets neither imposes substantive standards for the listing of its securities, nor does Pink Sheets regulate the market. To be quoted on Pink Sheets, a company simply finds an SEC-registered market maker who is a member of the NASD and who is willing to quote the stock. As a lister of stocks that include firms with low capitalization and day-to-day market volume, Pink Sheets may be an attractive venue for manipulative activity. Further, some offerings of stock may be modest enough to not require formal SEC registration and regular reporting. While Pink Sheets-listed companies are still subject to the requirements of the securities laws, the absence of registration means that they are more difficult to oversee, and an absence of regular SEC disclosure reports provides fewer opportunities for prosecution of misleading or incomplete statements made to investors. ${ }^{9}$ Finally, smaller companies may have fewer resources to monitor and police unusual trades of their stock in the marketplace.

Perhaps due to the lack of publicly available bulk historical trading data, there has been relatively little research on Pink Sheets stocks (Macey, O'Hara, and Pompilio (2004)). Upon our request, Pink Sheets, LLC provided us with archival data from January of 2004 through July of 2005 on the price, volume, and bid-ask spreads for all the stocks

concatenation of his own personally-received spam and that received by other e-mail addresses he has created specifically for the purpose of drawing spam. Both Böhme \& Holz (2006) and Hanke and Hauser (2006) use data from January 2005 through December 2005; the former study uses 21,935 of Richardson's touts, while the latter does not specify the total number of touts they examine. Our tout data are derived from reports of spam of global internet users in the more comprehensive NANAS database.

${ }^{9}$ Financial data for companies listed on Pink Sheets is limited, though a dealer is required to examine some of the financial statements before quoting the stock. Thus, for the stocks we study, it may be possible to obtain Rule $\S 240.15 \mathrm{c} 2-11$ filings. Future research might seek to uncover correlations between company financial data and susceptibility to spammed stock touting. 
we found touted in our sample. We did not have ready access to standardized accounting data on the touted firms,${ }^{10}$ making it nearly impossible to match firms based on specific characteristics such as book-to-market value. ${ }^{11}$ Thus, we also acquired data on 1000 randomly selected Pink Sheets securities. We use this sample as a set of control firms in our analysis. Because one stock had a price of $\$ 130$ (whereas the $99^{\text {th }}$ percentile price of the touted stocks was $\$ 8.35$ ), we imposed the conservative restriction that the price of all control stocks be less than $\$ 15$ so that the control sample was reasonably aligned with the touted stocks. After ensuring that none of the randomly selected Pink Sheets stocks had been reported as having touting activity over our sample period, 525 control stocks remained. ${ }^{12}$

In reviewing the data, we find that spam touts typically occur in temporal groups - NANAS reports indicate that touting is on average made over a course of a few days. This might not represent intentional continuing touts by the spammer, but rather the fact that much spamming takes place by "zombie" PCs that are infected with viruses and then instructed to send the spam. Once the spam is sent, the spammer may have little incentive to retract the original instructions sent to the zombie, since the zombie's future actions are no longer relevant to a completed market manipulation scheme.

In our analysis we cluster tout spam that continued for a few days: we label each period of continual touting as a "group." For example, if a given stock is touted for three consecutive days, the three days of touting would be denoted as one group. Similarly, if a stock is only touted on one day, that day forms its own group. We identify any instances

\footnotetext{
${ }^{10} \mathrm{We}$ first sought to obtain pricing and market data freely accessible online, but found such sources as Yahoo! Finance market data to be incomplete. Böhme \& Holz (2006) found the same problem, and were compelled to reduce their sample size of touted stocks from 391 to 111 tickers (and from 21,935 to 7,606 spam e-mails) because of unavailable data.

${ }^{11}$ Böhme \& Holz (2006) faced the same problem in finding a suitable market baseline to which to compare touted stock activity. They chose daily market indices: Standard \& Poor's 500, NASDAQ Composite, and Russell's daily microcap, which includes stocks with comparatively low liquidity. We choose the approach described within this paper to avoid the mismatch between these indices and the lightly-traded and thus volatile individual stocks that are the target of touters, but also compare with the Russell microcap for robustness.

${ }^{12}$ Later in the analysis, this number is further reduced because price or volume data was not available for the date of comparison with a touted stock.
} 
of more than five consecutive trading days without any further touting as the end of a group (our results are not sensitive to changing the length of this period). Within each group, we also identify the peak day of touting, represented by the day with the largest number of recorded touts in that group. Though we cannot observe the trading behavior of the spammer, for the purposes of testing whether spamming can be profitable to the touter, we take the peak day of spamming (day zero in the analysis that follows) as the one directly intended by the spammer in which to initiate selling the stock. To the extent that the day of heaviest touting does not correspond with the day the spammer planned, since control over e-mail distribution by zombie PCs may be inexact, the spammer may profit less. In this circumstance, however, we will see that the correlation between heavy touting and market behavior remains - the market responds to the actual volume and concentration of touts as they happen, regardless of when they were intended by the spammer to happen.

\subsection{Method}

After matching the Pink Sheets price and volume data with the tout data, for each touted stock on the day of the tout, we randomly select one stock from the randomly selected set of Pink Sheets non-touted stocks to serve as a control stock. The number of observations for our control firms does not exactly match the number for our touted stocks since Pink Sheets securities are usually thinly traded, and sometimes not traded at all. If no data are available, we drop the stock from the sample. In Table 1, we present summary statistics for the full sample, the touted stocks, and the control stocks. On average, prices for the touted stocks are significantly lower than for the control stocks. Specifically, the mean price for touted stocks is $\$ 0.67$, while that for the control stocks is $\$ 0.99$. This difference is statistically significant, as indicated by a $t$-statistic of -3.19 . Share volume for touted stocks, however, is slightly higher than it is for control stocks (2.88 v. 2.24 thousand, respectively). A $t$-statistic testing for a difference in mean volume suggests that this difference is also significant $(t=7.84)$. For completeness, we report the statistics on 
bid-ask spreads where they are found, but these numbers shed little light on the analysis except to emphasize the frequent illiquidity of the stocks. The spread information is for unconsummated transactions, and alone does not indicate how much was paid by a buyer or accepted by a seller for any shares of the stock analyzed. Standard deviations are enormous, and means and medians for price and spreads, in particular, are significantly different, suggesting a presence of outliers and a skewed distribution. In the next section, we examine the statistical as well as the economic significance to mitigate the concern that might accompany such data volatility. Specifically, we use generalized least squares regressions with clustered standard errors to examine the relationship between returns and trading activity around touting activity. Statistical significance persists despite the presence of such large deviations.

\section{Results}

\subsection{Primary Results}

We begin our analysis by examining whether a tout results in abnormal trading volume. Table 2 shows that it does. To perform this exercise, we note that we have stocks that are touted at some point during the sample period (touted stocks), as well as stocks that are never touted during the sample period (control stocks). Moreover, there are some days in our sample when no stock is touted (Tout Day $=$ No), and some days in our sample when there is a stock tout (Tout Day $=$ Yes). Table 2, Panel A shows the likelihood of a touted or control stock having the greatest dollar value of trading activity (i.e., price multiplied by volume) on a day when there is or is not touting. ${ }^{13}$ For our sample, on days when there actually is a stock tout (Tout Day = Yes), it is much more likely that one of

\footnotetext{
${ }^{13}$ To do this analysis, on each day, we rank stocks by dollar value of trading activity. We form a new dataset which keeps only the most actively traded stock from each day. We then generate the values in Table 2 by obtaining summary statistics from this new sample for each type of stock (touted or control) on each type of day (tout day or not). The analysis is done similarly in Panel B, using dollar value of abnormal trading activity. Note that ranking by different variables in Panels A and B yields a different number of observations for each type of stock/type of day.
} 
the touted stocks (as opposed to one of the control stocks) is the stock with the highest dollar value of trading activity: $70 \%$ vs $30 \%$. Instead, on days when there are no touts (Tout Day $=$ No), one of the control stocks is much more likely to be the most actively traded stock: $96 \%$ vs 4\%. Table 2, Panel B is similar but measures trading activity in terms of dollar value of abnormal trading activity (price multiplied by abnormal volume, where abnormal volume is a stock's volume on day $t$ less its mean volume over the sample period, standardized by mean volume). This panel shows that on days when the sample stocks are touted, the probability of one of them being the most actively traded stock is significantly higher than it is for one of the control stocks (74\% vs $26 \%$ ). On days when there is no touting activity, it is much more likely that one of the control stocks is the most actively traded stock (63\% vs $37 \%) .{ }^{14}$ These results suggest that touting does cause trading activity.

We present summary statistics for our touted stocks and the set of control stocks in Table 3. The number of observations for our control firms does not exactly match the number for our touted stocks since Pink Sheets securities are usually thinly traded, and sometimes not traded at all. If no data are available, we drop the stock from the sample. To verify that our results are not driven by thinly-traded stocks and bid-ask bounce, we evaluate midpoint returns. Because of the issue with reported closing spreads discussed above, however, we confirm in unreported results that these numbers are similar if we simply use closing prices to calculate returns. Additionally, because we anticipate that investors who receive spam may buy the touted stock on the day they receive the e-mail or may purchase the subsequent day, in the analysis that follows, we examine return behavior up to two days following the touting. ${ }^{15}$

Over the period from the day before touting activity begins through the peak

\footnotetext{
${ }^{14}$ Though one might infer from Table 2 that spammers tout specifically during low volume periods for their stock, which may also correspond to periods of low trading activity for the market as a whole, we note that in this initial analysis we do not distinguish between days with only one tout versus those days with several touts for a given stock. We address this issue later in the paper.

${ }^{15} \mathrm{We}$ also examine returns on the following day (as opposed to the following two days) and find that returns are still significantly lower than they are for the control group.
} 
day of touting, returns for touted stocks are, on average, 70 basis points higher per day than they are for control stocks. However, following the peak day, average returns are 1.06\% lower per day for touted stocks. Again, note that these are midpoint returns, so they are unlikely to be driven by bid-ask bounce. In Section 4, we examine potential profits and losses to spammers after accounting for anticipated transaction costs. The difference in returns to touted stocks relative to non-touted stocks leading up to peak day is significantly positive at the $10 \%$ level $(t$-statistic $=1.74)$ and, subsequent to peak day, this difference is significantly negative $(t$-statistic $=-3.55) .{ }^{16}$ We also consider "benchmark-adjusted" returns rather than simply compare them to a set of control stocks. Pink Sheets stocks are dissimilar from those within the stock indices traded on a major exchange, so finding an appropriate benchmark with which to adjust returns is difficult. Nonetheless, we compare returns with the return on Russell Micro-cap Index. Results are qualitatively unchanged, and are available upon request. ${ }^{17}$

Volume is significantly higher on the peak day of touting for touted stocks than it is prior to the peak day - average abnormal volume increases by over $50 \%$ from 0.40 during the period before to 0.65 on the peak day of touting activity - suggesting that touting induces trading activity. ${ }^{18}$ We interpret our results to suggest that spammers tout the stock in order to encourage buying pressure and trading activity, making the stock liquid enough to sell (see Baker and Stein (2004)).

Thus far, our results accord with the notion that after a modest but positive price increase - possibly one caused by their own anticipatory buying of the sort in which Lebed engaged (In Re Lebed (2000)) - spammers tout stocks. Reflecting sell activity that outstrips spam-induced temporary demand, returns for touted stocks subsequently

\footnotetext{
${ }^{16}$ Because we use "groups" of touts as a single event, we are not concerned about correlation arising from overlapping observations affecting our results. Nonetheless, in the regressions that follow, we do correct for possible clustering across observations.

${ }^{17}$ The average beta resulting from a regression of each touted stock's return on the Russell Micro-cap Index return is statistically and economically indistinguishable from zero.

${ }^{18}$ We do not present data on relative spreads in this table, because later in the paper we specifically evaluate a strategy that takes spreads into account. We do note, however, that there is little variation in spreads within a touting "window," and that relative spreads are significantly lower for touted stocks.
} 
fall. Figures 2 and 3, respectively, depict returns and abnormal volume for the touted and control stocks in our sample. For touted stocks, there is a clear pattern that returns increase through the peak day of touting and deteriorate after, while abnormal volume is the greatest on the day of and the day after the peak day of touting. There is no such pattern for the control stocks. Because the negative returns following touting activity may have nothing to do with the touting per se, but may just be a simple reversion or price correction after an increase independent of touting activity, we match each touted stock with non-touted stocks that have a similar increase in price on the days leading to peak touting for the touted stocks. Matching our stocks to other Pink Sheets stocks proved difficult because they are so thinly traded. As an alternative, we match each touted stock with one stock from NASDAQ such that the matched stock is the smallest stock with the most similar price increase over the relevant days. By construction, the average price increase for the NASDAQ stocks leading to the peak day of touting is statistically indistinguishable from that for the touted stocks, but touted stocks subsequently, and significantly, underperform the matched set of NASDAQ stocks. ${ }^{19}$ This evidence is consistent with the idea that it is the manipulation of trading activity via spam, coupled with selling by spammers, that generates a systematic negative return.

Buying by spam recipients need not reflect their belief that the tout is true. Investors who attach even a small probability that price or volume changes are generated by private information may still trade, which can cause price changes that are unrelated to fundamentals (Grossman (1989)). Allen and Gale (1992) also show that, even in a rational framework, so long as investors attach a positive probability to a stock promoter being an informed trader, the manipulator, whether informed or uninformed, can profit. As long as an investor believes there will be some response to touting, he may want to buy even if he knows spam is uninformative, believing that it is still early in the pyramid scheme and that other recipients will drive the stock price even higher. Our data do not allow us to distinguish between this model and one in which much of the buying is

\footnotetext{
${ }^{19}$ These results are available upon request. Later in the paper, we also match touted stocks to small NASDAQ stocks by price and trading activity. See Section 3.2.
} 
motivated solely by the belief that spam reveals information about a stock's future price movement.

The standard deviation of our price data is high, reflecting the volatile nature of the Pink Sheets listings, so estimates from our analysis are likely to be noisy (see also Macey, O'Hara, and Pompilio (2004)). We therefore run a pooled cross-sectional generalized least squares regression using all observations in our sample period and adjust our statistics for data clustering. ${ }^{20}$ We first examine daily midpoint return as the dependent variable. The left hand side of Table 4 refers to the full sample (20042005). From Panel A, we see that the coefficient on "\#touts," which represents the number of touts on the day the return is measured, is significantly positive, $0.10 \%$. This suggests that each additional tout is associated with an increase in daily return of 10 basis points. Additionally, looking at what happens in the combined 5 days after the tout ("cum5"), we see that subsequent returns are significantly negative (p-value $<0.0001)$. The results from the regression are consistent with our hypothesis of why people spam, and the volume regressions shown in Panel B appear to provide supporting evidence. The negative coefficient on the variable "tstk" in the full sample suggests that, on average, touted stocks have slightly lower abnormal volume than do the control stocks. The significantly positive coefficient on "\#touts", however, indicates that touting does have a significantly positive effect on volume. In this sample, abnormal volume increases by almost $1 \%$ with each additional tout. This abnormal volume associated with touting remains high in the 5 days following the touting activity.

We also examine our results in the 2004 and 2005 subperiods (shown in the respective middle and right hand columns). An interesting pattern emerges: in 2005 volume reacts significantly more to touting activity. Abnormal volume increases by $1.16 \%$ with each additional tout in 2005 , though only by $0.68 \%$ in 2004 . Though one might think that the general public would learn over time, resulting in a smaller reaction to touting,

\footnotetext{
${ }^{20}$ In our regressions, we cluster by both ticker and date. That is, we correct for the possibility that returns on a given date may be correlated across stocks, and that, for a given stock, returns around touting activity may also be correlated.
} 
it appears that touters may be the ones who learn over time. Additionally, increased buying by spammees makes it easier for spammers to sell, which may increase volume further. The fact that returns on the tout day are not as sensitive to each additional tout (14 basis points in 2004 v. 3 basis points in 2005) is consistent with this idea that at least some of the spammees' buying activity is offset by spammers' selling activity such that the net effect on returns is marginal. An increase in sheer volume of spam may also account for increased buying. In January 2005, 0.8\% of spam e-mails were stock touts, and from January 2005 through June 2005, the proportion of spam that touted stock is said to have increased by $10 \%$ per month. ${ }^{21}$

Table 5 allows us to further analyze the results in Table 4 by considering touted stocks only. (Since all stocks in this analysis are touted stocks, we omit the variable "tstk" from our regressions.) Results for daily midpoint returns and abnormal volume are given in Panels A and B, respectively. As above, the left hand side of the table refers to all data (2004-2005), the middle column provides results for 2004, and the right hand side of the table gives results for 2005. The results are similar to those presented in Table 4: during the full sample period, returns increase by a statistically significant 9 basis points with each additional tout but are significantly lower in the following days. Abnormal volume increases by nearly $1 \%$ with each tout on touted days and remains high following the tout. Subperiod results for returns and volume follow the same pattern as in Table 4. The effect of each additional tout on abnormal volume is over 50 basis points greater in 2005, though the effect of each additional tout on tout day returns is insignificant.

Within the group of touted stocks there is great variation on the amount of touting that takes place, both in sheer number of messages (as represented by multiple reports of the same spam to NANAS) and in messages over time. Table 6 explores how returns and the overall economic effect (measured by the dollar value of transactions in a given day)

\footnotetext{
${ }^{21}$ See "Sophos identifies the most prevalent spam categories of 2005," August 3, 2005, available at $<$ http://www.sophos.com/pressoffice/news/articles/2005/08/pr_us_20050803topfivecats.html> and "Sophos reveals 'dirty dozen' spam relaying countries," July 24, 2006, available at <http://www.sophos.com/pressoffice/news/articles/2006/07/dirtydozjul06.html>.
} 
are affected by the specific amount of spam touting, testing the hypothesis that more reports of stock touting in NANAS on a given day for a given stock represent a more successful touting effort by the spammer, that results in a greater impact on the market for the touted stock. To evaluate this possibility, we split stock-days into quintiles based on quantity of touting. Table 6 shows that the average number of touts on a given day for a given stock is 1 for those stock-days in Quintile 1. By construction, this number monotonically increases to 31.44 for the quintile including those stock-days with the greatest amount of touting (Quintile 5). The average return is not significantly different on the tout day (presumably because increases in volume are from both spammers and spammees (or, buyers and sellers, respectively)), but both dollar value of trading activity and dollar value of abnormal trading activity increase substantially. Sattherwhite difference in means tests indicate that both dollar value of trading activity and dollar value of abnormal trading activity are significantly greater for the most actively touted quintile; respective $t$-statistics are 5.00 and 1.84. The fact that the overall dollar value of transactions roughly increases with touting activity suggests that the economic effect of touting is larger on those days with more touting activity. This distinction is important because many Pink Sheets stocks are penny stocks so a price increase from, say, \$0.01 to $\$ 0.03$ is $200 \%$, whereas a price increase from $\$ 1$ to $\$ 1.05$ (which is a greater dollar increase) is only a $5 \%$ return. Since it represents the total dollar size of the stock's market on a given day, the price-multiplied-by-abnormal volume measure accounts for the fact that lower price stocks can end up with huge returns. Nonetheless, on a given day, there is, on average, approximately $\$ 1,954.69$ more traded in strongly touted stocks than in weakly touted stocks $(\$ 3,439.20$ v. $\$ 1,484.51)$. Figure 4 depicts the magnitude of the effect. Table 6, Panel B gives summary statistics on returns, abnormal volume, and relative spreads for the most actively touted quintile of stocks. Note that the sample size is greater than one-fifth of the original sample of tickers because these are the most actively touted stocks, and any given stock may have more than one observation. In particular, we see that leading up to the peak day, mean midpoint holding period returns 
(from the day before the touting begins to the peak day of touting) are $3.42 \%$ greater for heavily touted stocks than for control stocks. Subsequently, however, average returns are roughly $7.61 \%$ lower for touted stocks. The increase in abnormal volume on peak day doubles from the period prior to peak day for touted stocks, whereas abnormal volume for control stocks actually decreases.

It appears that, despite the volatile and unpredictable behavior of Pink Sheet stocks, touting activity indeed has explanatory behavior for both returns and trading activity. It is an empirical regularity that news impacts liquidity (trading activity increases after earnings announcements, causing spreads to decrease; see Baker and Stein (2004) or Barber and Odean (2005), among others). At the same time, Pink Sheets is "off the beaten path" in that many investors are unaware of the existence of most Pink Sheet stocks. Our results suggest that one way for an investor trading on Pink Sheets to change his or her position is to create liquidity, and this is fairly easily done by attracting attention to the stock via spam. These results buttress the assumption underlying the Merton (1987) model that investors can only invest in stocks in which they are familiar. Overall, our results are consistent with the concurrent working paper by Böhme and Holz (2006) who suggest that, in data from 2005, a significantly positive abnormal return accompanies spam messages but disappears within four days; our results also accord with the findings in the concurrent working paper by Hanke and Hauser (2006) who, using data from 2005, show that stock spam affects returns, volume, volatility, and spreads.

\subsection{Robustness Checks}

We perform several robustness tests. We mentioned that we matched the touted stocks in our Pink Sheets sample with stocks in the smallest decile of NASDAQ firms. These results suggest that for leading up to the peak day of touting (i.e., in the period "beg 1 to peak"), touted stocks statistically and economically outperform the control stocks; but, subsequently, they statistically and economically underperform the control stocks following the peak day of touting (i.e., in the period "peak to end +2 "). 
As an additional check, we hand collect the industry data for each touted firm in our sample from Pink Sheets. We match each of these firms with one from the same industry (determined by 2-digit SIC code) and repeat the analysis. It is interesting to note the distribution of firms across industries. We see from Table 7 that over one-quarter of the touted firms (26.63\%) are from the Business Services industry. The Communications industry accounts for approximately $7 \%$ of the sample, as does Engineering, Accounting, Research, Management, and Related Services. Table 8, Panel A provides information similar to Table 3, Panel A, but matches our firms by industry.

Using this alternative control group leads to even more significant results than in the original sample. In particular, we see that touted firms, on average, perform over $1 \%$ better per day during the period "beg - 1 to peak", while in the period "peak to end +2 ", they underperform by approximately $1 \%$ per day. The $t$-statistics testing for a difference in mean return between these two groups are 3.31 and -3.77 , respectively. ${ }^{22}$

To check our findings on negative returns, we match stocks based on price and abnormal volume on the day preceding the peak day of touting. The notion is that stocks that have a lot of volume may experience abnormally high returns (see Baker and Stein (2004)). This being the case, a subsequent reversal may just be a result of the stock "cooling down." Yet when we perform the analysis matching on similar priced NASDAQ stocks with similar average daily dollar volume (prior to the touting), the results remain qualitatively unchanged. In particular, from the day before touting through the peak day of touting, touted stocks, on average, outperform control stocks by 139 basis points

\footnotetext{
${ }^{22}$ We also check if any of our touted stocks are touted by e-mail spam on days that they also appear on the RagingBull.com message board (as per Antweiler and Frank (2004)). We do this to consider whether touting may serve as a means to capture investor attention, incremental over the ability of message boards to do the same. Results for firms that are touted and on RagingBull.com are available upon request, but suggest that accounting for the overlap between the touted stock sample and the sample of stocks that are also mentioned on message boards does not qualitatively alter our findings. We also gathered information from Yahoo! and Silicon Investor. Only two of our observations overlapped with messages in Yahoo! (by ticker-date), and only scarce news for a subset of the period studied in our paper was available on Silicon Investor. We also search www.google.com, Factiva, and Lexis Nexis for news articles about the companies in our sample on days they are touted, but find no systematic correlation between news and touting activity.
} 
per day. A $t$-statistic of 3.49 indicates this difference is significant. From the peak day of touting through the 2 day period after the touting ends, again, the touted stocks significantly underperform even this set of control stocks, on the order of 156 basis points per day. This difference is also statistically significant $(t=-4.29)$.

\section{Discussion}

The evidence presented in Section 3 suggests not only that some investors actually do respond to spam stock touts, but they respond in ways that affect the overall market for the comparatively illiquid stocks that are the favorites of spammers. The returns rise with the initial touts and then fall immediately after. In this section we seek to quantify the magnitude of the effect. To perform this analysis, we examine the price reactions to stocks that are "effectively" touted. In particular, for each group of stock touts, we determine the average daily concentration of touting. If a stock is touted twelve times in a three-day window, the average concentration is four; if a stock is touted six times over a six-day period, its average concentration is one. We then rank groups by average concentration and examine return and volume reaction over the touting period for the $50 \%$ of groups that have the most concentrated touting.

First, let us consider an example from the point of view of the spammer. To follow this example, refer to Table 9 (sub-panel labeled "beg - 1 to peak"). ${ }^{23}$ We use the stock's daily closing price as reported by Pink Sheets as an indicator of what a buyer paid or a seller earned on a stock transaction consummated that day. From that baseline we then adjust the spammer's profit for transaction costs (ranging from 0 to 10, and also 100, round-trip basis points). ${ }^{24}$ While buying stock earlier might provide

\footnotetext{
${ }^{23}$ As was the case in Table 6 , because we are dealing with the most extensively touted stocks, a given stock may have several touting periods (groups) that have a high concentration of touting. This explains why the sample size is not equal to $50 \%$ of the sample size in Table 3.

${ }^{24} \mathrm{We}$ considered assuming that the spammer buys at the ask price on the day before beginning his touting, and then liquidates at the bid price on the peak day of touting. However, because Pink Sheets stocks are so thinly traded, the closing bid and ask data provided to us by Pink Sheets can not reliably be associated with a recorded transaction the following day. Moreover, a spammer concerned about
} 
more of an opportunity to buy low, keeping the buying and selling tightly anchored to the touting might prove an attractive strategy because the touter's money would not be tied up in one stock for too long. It might initially appear that because Pink Sheets stocks in general, and the targets of touters in particular, tend to be illiquid, a spammer would only be able to transact a small dollar amount at the quoted prices. Our tracking of volume shows, however, that liquidity is improved significantly during heavy tout periods. Therefore, if the spammer (or the spammer's client) were to invest according to this basic practice and to tout enough to create sufficient liquidity of a given stock, returns in this table suggest that his or her net worth would increase approximately $4.29 \%$ in roughly two days, before transaction costs. Assuming a spammer were to invest $\$ 1,000$ in each of the touted stocks in this sample, expected profits would be nearly $\$ 18,018$, before transaction costs. ${ }^{25}$ If we were to assume a round-trip transaction cost of $2,4,6$, 8 , or 10 basis points, respective average profits would decrease to $\$ 17,932.20, \$ 17,846.40$, $\$ 17,760.59, \$ 17,674.79$, or $\$ 17,588.99$. And, even if we considered a round-trip transaction cost of $1 \%$, a spammer's expected profit would remain significant at $\$ 13,727.91$. Results are presented in the lower sub-panel of Table 9. Of course, the volatility of returns (measured by standard deviation) is higher for touted stocks. Depending on the touter's risk aversion level, the greater return may more than compensate for bearing this added risk.

Now let us consider the returns to an investor who follows the advice of a spammed tout. Again, refer to Table 9 (sub-panel labeled "peak to end +2 "). On average, if the victim were to purchase the touted stock at the closing price on the peak day of touting and sell it at the closing price two days after the touting window ends, he or she would lose $5.37 \%$ before transaction costs. Of course, we do not know that the spammee would sell the stock 2 days after the touting ends, but casual observation suggests that the Pink

profits is likely watching the market closely to determine the best price at which to unload a position. This price is unlikely to be the previous day's closing ask so, if anything, by using closing prices, we may be understating the profit to the spammer.

${ }^{25}$ On average, the spammer makes $4.29 \%$ on the 420 investment opportunities. It follows that $\left(\$ 1000^{*} 420 * 1.0429\right)$ - $(420 * \$ 1000)$ would be the spammer's net gain. 
Sheets stocks do not return to the price level on the day of peak touting for some time. In the same column, we can see that, if each time the victim saw a touted stock he or she invested in a randomly selected non-touted Pink Sheets stock, he or she would face marginally lower idiosyncratic risk and, on average, would make $2.44 \%{ }^{26}$

The above discussion accounts for spreads but does not include brokerage fees, which are often flat for the entire transaction irrespective of volume. ${ }^{27}$ Spammers who buy and sell in large amounts of money can calibrate the size of their trades accordingly to make sure they profit despite the broker's fee, while naïve spammees who respond to touting activity are unlikely to be sophisticated enough to minimize these costs (see, for example, Barber and Odean (2000)).

Overall, our results imply that, in theory, a spammee could profit by forming a zero-cost portfolio that entails buying non-tout stocks and shorting tout stocks each time he or she receives a spam touting stock. This strategy would have a high expected return $(7.92 \%) .{ }^{28}$ Since Pink Sheets stocks are so thinly traded, however, the spammee is at a disadvantage to the spammer. He or she could not easily borrow the stock necessary to short it and he or she does not have the same tools to ensure liquidity when selling.

\footnotetext{
${ }^{26} \mathrm{It}$ is worth noting that $2.44 \%$ is an extremely large return for a typical control sample during the period "peak to end +2 ". Looking at how the returns to the alternative control samples from NASDAQ compare to those from the original Pink Sheets control sample (Table 8 and Table 3, respectively) sheds some light on this issue. In particular, it appears that most NASDAQ stocks have a very low average daily return (Table 8, Panel A). However, when we examine returns to a NASDAQ matched sample based on price and abnormal volume (Table 8, Panel B), we see that the returns over this period are much more similar to (and in fact larger than) those for the Pink Sheets control sample, which suggests these returns may be compensation for holding extremely low-priced, low-volume, and high-volatility stocks.

${ }^{27}$ For example, E*TRADE offers flat fees as low as $\$ 6.99$ per order, with no apparent extra fees for trading additional shares of stocks, such as these, not listed on a national securities exchange.

${ }^{28}$ This high expected return is likely at least partial compensation to investors for holding relatively illiquid and small stocks (see, for example, the discussion about an illiquidity premium in Brennan and Subrahmanyam (1996)).
} 


\section{$5 \quad$ Policy Implications}

We briefly consider some policy implications of our finding that stock prices can be successfully manipulated through spam. In the United States, the prevailing model of consumer protection is that of disclosure. Those who give advice to the public about stocks run the risk of sanction by the federal Securities and Exchange Commission or its state counterparts if they fail to disclose such facts as a material interest they have in the stocks themselves. ${ }^{29}$ Interestingly, much of the stock-touting spam we examine, such as the sample provided in Figure 1, contains boilerplate disclosures such as the statement that the spammer had been compensated a certain amount of money and shares of stock by a third party to send out an optimistic tout, and that the spammer (and the third party) were likely to be selling the very stock touted contemporaneously with the tout itself. In order for a touter's (or other entity recommending stocks) substantive claims to run afoul of the S.E.C., a reasonable person must be thought to believe that the claims are both true and significant (Langevoort (2002)). This standard turns out to exculpate much of the touting that takes place in the spam we examine. Section 10 of the Securities and Exchange Act of 1934 prohibits "manipulative or deceptive devices" connected with the sale of securities, and forged headers in the typical spam e-mail may suffice for this. However, the headers of such e-mails are usually from such clearly nonexistent persons that they are better described as anonymous than fraudulent. ${ }^{30}$ Those e-mails that purport to be private e-mail between two parties, "accidentally" sent to the real target through spam, might of course fall under this provision. Pink Sheets C.E.O. R. Cromwell Coulson has called attention to this type of market manipulation, highlighting

\footnotetext{
${ }^{29}$ Some stock tout spammers have been prosecuted under section 17(b) of the Securities Act of 1933, on the basis that the spammers did not sufficiently disclose their financial interests (see, e.g., In Re James Sheret, Jr., Lit. Rel. No. 16451, 71 S.E.C. Docket 1787 (Feb. 24, 2000)). Walker and Levine (2001) write that after the S.E.C. began to bring enforcement cases, disclosure "markedly improved." Many of our recorded spam reflect that improvement - if improvement it is.

${ }^{30}$ Langevoort (2002) writes that "[t] he fact that a pseudonymous person on a web site says, even repeatedly, that he thinks that a stock is poised to gain an immense amount does not by itself convey any seemingly reliable information. In other areas of antifraud litigation under the securities laws, the courts have dismissed claims involving far more substantive assertions of general optimism than this even when made by corporate insiders - as immaterial as a matter of law."
} 
the inadequacy of such disclosure, and has asked the S.E.C. to consider rules that would make this type of stock touting much more difficult. ${ }^{31}$

Given the disclosure statements, the fact that so much spam is blocked by spam filters, and the additional effort it takes a recipient to place an order, it is striking that heavy stock touting can actually work. If junk e-mail can find its way through ISPs and client-side filters to the eyes of Internet users, what kind of response rate might be expected? For spammers wanting recipients to read and then take some action on the basis of an e-mail, even a very small response rate might be enough to justify the modest effort and expense required to send it. ${ }^{32}$ Our data suggest a very low response rate for stock spam, which further highlights the difficulties of combating these schemes using ex post regulatory intervention; ${ }^{33}$ the effort required to vindicate the interests of a few manipulated investors may not be worth it, and the amount of money made on any given campaign may be modest enough to rate a correspondingly low priority on an enforcement agenda. Yet the problem is significant, as the increasing volume of stock touting spam and apparent number of campaigns suggests - spammers can make a lot of money over time, in amounts that are small enough to escape notice but large enough to be worth accumulating. This suggests that structural solutions designed to lessen the impact of stock spam may be better than traditional enforcement.

If disclosures meet the requirements of law and yet consumers are still so readily taken in, regulators might consider more aggressive, and paternalistic, applications of

\footnotetext{
${ }^{31}$ See R. Cromwell Coulson, Petition for Commission Action to Protect the Investing Public from Unlawful and Deceptive Securities Promotions, April 2006, <http://sec.gov/rules/petitions/petn4519.pdf>.

${ }^{32}$ Studies such as Karpatkin (1999) suggest that children and teenagers are "easily manipulated" so are vulnerable to marketing ploys like spam. Yet, given that Barber and Odean (2000) find that the average age of the principal account holder in their sample is approximately 50, it is unlikely that the people Karpatkin is concerned for are responsible for the trading activity covered in this paper.

${ }^{33}$ For China World Trade Corp., the most aggressively touted stock in our sample, our data suggest a total dollar value of trading activity of $\$ 36,842.43$ on its heaviest day of touting. If we suppose that the average investor invests $\$ 100$, since dealers do not double count orders, then we would expect approximately 360 people to be trading. If we further assume that 10 million spams are sent out for a given stock, then approximately 36 people per million are responding. This is an extraordinarily low response rate, even as trading is noticeably affected.
} 
law to prohibit such conflicts outright, rather than simply requiring disclosure. These could include requiring additional transactional steps before individuals are permitted to trade in penny stocks, similar to the written assurances that brokers require from their clients before permitting them to pursue risky and complex investment activities such as writing uncovered options. Such steps might suffice as a cooling off period between the receipt of a tout and acting upon it. Spammers, to be sure, might then take up more sustained touting campaigns in order to maintain interest across such cooling off periods.

Disclosure has not been deemed sufficient to protect users in other sectors. For example, the mere disclosure of odds (and fidelity to them) is typically not legally sufficient for casinos to offer standardized games of chance to the public; instead, regulators impose minimum payouts by such games to the public, presuming that many members of the public would not shop among casinos for the best odds if the casinos had a free hand to set them. Just as casinos must go beyond disclosure and provide minimum government-mandated "fair" returns to those who gamble, stock touters might be prohibited from trying to move markets to their advantage using the wealth of unsophisticated investors, even if they fully disclose their bias - in essence, conceding the swindle they seek to accomplish in text alongside the touts that are central to the enterprise.

Finally, those who tout stocks using spam might be singled out for enforcement under the CAN-SPAM Act, since our review of the spam e-mails indicate failure to abide by CAN-SPAM's labeling and opt-out requirements.

\section{Conclusion}

Based on an archived database of touts drawn from 75,415 likely e-mail tout messages, themselves drawn from over 1.8 million reports of spam, we document a significantly negative return following days of heavy spam touting of a stock. We provide evidence of an average positive return over the period that begins the day before touting is initiated 
through the peak day of touting activity. Volume responds positively and significantly to touting. The evidence is consistent with the notion that spammers tout stocks to increase demand and perhaps price enough to unload previously-secured positions at a profit. Selling pressure on the part of the spammer then results in negative returns following intense touting. The implication of this is that the investors who respond to heavy touting are, on average, losing approximately $5.50 \%$ over the few days that follow aggressive touting. When aggregated across touts, the dollar value of this loss may be significant. The fact that losses are greater for those stocks that are touted most heavily underscores the notion that heavy touting via spam can have an effect on trading activity and returns. Our results also accord with a model put forward in Hong and Huang (2005) where insiders who participate in highly illiquid markets may engage in costly activities in order to liquidate their positions without significant price impact.

Overall, our analysis shows that spam works. Among its millions of recipients are not only those who read it, but who also act upon it, suggesting a value to spamming that will create a powerful counterbalance to regulatory and technical efforts to contain it. 


\section{$7 \quad$ References}

Aggarwal, Rajesh and Guojun Wu (2003), "Stock Market Manipulation - Theory and Evidence," Working paper.

Allen, Franklin and Douglas Gale (1992), "Stock-Price Manipulation," Review of Financial Studies 5, $503-529$.

Antweiler, Werner and Murray Z. Frank (2004), "Is All that Talk Just Noise? The Information Content of Internet Stock Message Boards," Journal of Finance 59, 1259 $-1294$.

Barber, Brad and Terrance Odean (2000), "Trading is Hazardous to your Wealth: The Common Stock Investment Performance of Individual Investors," Journal of Finance 55, $773-806$.

Barber, Brad and Terrance Odean (2005), "All that Glitters: The effect of Attention and News on the Buying Behavior of Individual and Institutional Investors," Working Paper.

Baker, Malcolm P. and Jeremy C. Stein (2004), "Market Liquidity as a Sentiment Indicator," Journal of Financial Markets 7, 271 - 299.

Benabou, Roland and Guy Laroque (1992), "Using Privileged Information to Manipulate Markets: Insiders, Gurus, and Credibility, Quarterly Journal of Economics 107, 921-958.

Brennan, Michael and Avanidhar Subrahmanyam (1996), "Market Microstructure and Asset Pricing: On the Compensation for Illiquidity in Stock Returns," Journal of Financial Economics 41, 341 - 364 .

Böhme, Rainer, and Thorsten Holz (2006), "The Effect of Stock Spam on Financial Markets," Working paper.

Bushee, Brian and Christian Leuz (2006), "Economic Consequences of SEC Disclosure Regulation," Journal of Accounting and Economics, Forthcoming.

Busse, Jeffrey, and T. Clifton Green (2002), "Market Efficiency in Real Time," Journal of 
Financial Economics 65, 415 - 437.

Cooper, Michael, Orlin Dimitrov, and P. Raghavendra Rau (2001), "A Rose.com by Any Other Name," Journal of Finance 56, 2371 - 2388.

Coulson, R. Cromwell, Petition for Commission Action to Protect the Investing Public from Unlawful and Deceptive Securities Promotions, April 2006, $<$ http://sec.gov/rules/petitions/petn4-519.pdf>.

Cyr, Joshua (2005), "Spam Stock Tracker: How Much Can You Lose?", <http://www.spamstocktracker.com>.

Das, Sanjiv Ranjan, and Mike Y. Chen (2006), "Yahoo! For Amazon: Sentiment Extraction from Small Talk on the Web," Working paper.

Das, Sanjiv Ranjan, Francisco de Asis Martinez-Jerez, and Peter Tufano (2005), "eInformation: A Clinical Study of Investor Discussion and Sentiment," Financial Management Autumn, 103 - 137.

Froot, Kenneth A. (1989), "Consistent Covariance Matrix Estimation with Cross-sectional Dependence and Heteroskedasticity in Financial Data," Journal of Financial and Quantitative Analysis 24, 333355.

Grossman, Sanford (1989), The Informational Role of Prices, MIT Press.

Hanke, Michael, and Florian Hauser (2006), "On the Effects of Stock Spam E-mails," Working Paper.

Hong, Harrison, and Ming Huang (2005), "Talking up Liquidity: Insider Trading and Investor Relations," Journal of Financial Intermediation 14, 1 - 31.

In Re Lebed, Jonathan G. (2000), Securities Act Release No. 33-7891, Exchange Act Release No. 34-43307, 73 S.E.C. Docket 741.

In Re Sheret, James (2000), Lit. Rel. No. 16451, 71 S.E.C. Docket 1787.

Karpatkin, Rhoda H. (1999), "Toward a Fair and Just Marketplace for All Customers: The Responsibilities of Marketing Professionals," Journal of Public Policy and Marketing 18, 
$118-122$.

Langevoort, Donald C. (2002), "Taming the Animal Spirits of the Stock Markets: A Behavioral Approach to Securities Regulation," Northwestern University Law Review.

Lee, Charles M. C. (1992), "Earnings News and Small Traders: An Intraday Analysis," Journal of Accounting and Economics 15, 265 - 302.

Leuz, Christian and Robert Verrecchia (2000), "The Economic Consequences of Increased Disclosure," Journal of Accounting Research 38, 91 - 124.

Macey, Jonathan, Maureen O'Hara, and David Pompilio (2004), "Down and Out in the Stock Market: The Law and Finance of the Delisting Process," Working paper.

Merton, Robert (1987), "A Simple Model of Capital Market Equilibrium with Incomplete Information," Journal of Finance 42, 483 - 510.

Panchapesan, Venkatesh and Ingrid Werner (2004), "From Pink Slips to Pink Sheets: Market Quality around Delisting from Nasdaq," Working paper.

Richardson, "Stock spam effectiveness monitor", <http://www.crummy.com/features/StockSpam/>.

Walker, Richard H. and David M. Levine (2001), "You've Got Jail': Current Trends in Civil and Criminal Enforcement of Internet Securities Fraud," American Criminal Law Review 38, 405. 


\section{Table 1: Summary Statistics}

Table 1 presents summary statistics on price, volume, and bid-ask spread data for the stocks in our sample. Under the column "Stock", All refers to the full sample of stocks in our analysis, Touted refers to those stocks that are touted in an e-mail, and Control indicates randomly selected stocks from the Pink Sheets exchange for which there are no touts in our sample. For each ticker, we obtain the average of each variable (price, volume, etc.). The summary statistics in the table are based on those averages. Under \# Tickers, we give the number of unique companies in each sample. Price is closing price, Volume is share volume, Spread is the ask price less the bid on the closing trade, and \% Spread is spread/price. Difference represents the difference in means between the Touted and Control groups for each variable. $T$-stat refers to the Satterwhite $t$-statistic testing whether each difference in means is significant. All data are from January, 2004 - July, 2005.

\begin{tabular}{|c|c|c|c|c|c|c|c|}
\hline Variable & Stock & \# Tickers & Mean & Median & St Dev & Min & Max \\
\hline \multirow[t]{5}{*}{$\overline{\text { Price }}$} & All & 829 & 0.87 & 0.25 & 1.64 & 0.00 & 12.60 \\
\hline & Touted & 304 & 0.67 & 0.30 & 0.92 & 0.00 & 5.68 \\
\hline & Control & 525 & 0.99 & 0.22 & 1.93 & 0.00 & 12.60 \\
\hline & Difference & & -0.32 & & & & \\
\hline & T-stat & & -3.19 & & & & \\
\hline \multirow[t]{5}{*}{ Volume } & All & 829 & $2,471.32$ & $2,766.60$ & $1,255.52$ & 0.82 & $5,110.33$ \\
\hline & Touted & 304 & $2,876.40$ & $3,157.09$ & $1,001.03$ & 0.82 & $4,740.29$ \\
\hline & Control & 525 & $2,236.75$ & $2,370.32$ & $1,327.05$ & 3.55 & $5,110.33$ \\
\hline & Difference & & 639.65 & & & & \\
\hline & T-stat & & 7.84 & & & & \\
\hline \multirow[t]{5}{*}{ Spread } & All & 814 & 0.10 & 0.03 & 0.23 & 0.00 & 2.99 \\
\hline & Touted & 292 & 0.07 & 0.03 & 0.13 & 0.00 & 1.51 \\
\hline & Control & 522 & 0.11 & 0.03 & 0.27 & 0.00 & 2.99 \\
\hline & Difference & & -0.04 & & & & \\
\hline & T-stat & & -3.08 & & & & \\
\hline \multirow[t]{5}{*}{$\%$ Spread } & All & 812 & 0.25 & 0.17 & 0.29 & 0.00 & 3.09 \\
\hline & Touted & 291 & 0.19 & 0.14 & 0.17 & 0.00 & 1.37 \\
\hline & Control & 521 & 0.28 & 0.19 & 0.34 & 0.00 & 3.09 \\
\hline & Difference & & -0.09 & & & & \\
\hline & T-stat & & -5.05 & & & & \\
\hline
\end{tabular}




\section{Table 2: Initial Evidence on the Relevance of Touting for Trading Activity}

Table 2 presents summary statistics for the touted and control stocks in our sample on both days that experience a tout and days that do not. Panel A gives results defining dollar value of trading activity as closing price multiplied by share volume. Panel B provides data in terms of dollar value of abnormal trading activity, which is measured by closing price multiplied by abnormal share volume. Abnormal share volume for each stock is obtained by subtracting the stock's mean volume over the sample period from its daily dollar volume, standardized by its mean volume. If a "No" appears under the column labeled "Tout Day," then no stock is touted on that day, but if a "Yes" appears in the column, then there is a stock tout on that day. The column labeled "Stock" indicates whether the stocks for which the summary statistics are calculated are touted or control stocks. $\mathrm{N}$ gives the number of unique tickers in each group, $\mathrm{Pr}$ *Vol is the average of share price multiplied by share volume, $\mathrm{Pr} * \mathrm{AbnVol}$ is the mean of price multiplied by abnormal share volume. St Dev is the standard deviation of Pr*Vol (Panel A) or Pr*AbnVol (Panel B), and Percent indicates the proportion of times that the relevant type of stock (touted or control) is the most actively traded stock on the relevant day (touted or not touted). For the averages, ${ }^{*}$ denotes significance at the $\alpha=5 \%$ level. All data are from January, 2004 - July, 2005.

Panel A: Dollar Value of Trading Activity

\begin{tabular}{lrrrrr}
\hline Tout Day & Stock & N & Pr*Vol & St Dev & Percent \\
\hline No & Touted & 20 & $41,101.80^{*}$ & $8,508.38$ & 0.04 \\
No & Control & 446 & $56,152.06^{*}$ & $18,151.89$ & 0.96 \\
& Difference & & $15,050.26$ & & \\
& T-stat & & 7.21 & & \\
Yes & &. & & \\
Yes & Touted & 260 & $11,118.84^{*}$ & $10,853.53$ & 0.70 \\
& Control & 114 & $13,975.80^{*}$ & $11,982.90$ & 0.30 \\
& Difference & & $2,856.96$ & & \\
& T-stat & & 2.18 & & \\
\hline
\end{tabular}

Panel B: Dollar Value of Abnormal Trading Activity

\begin{tabular}{lrrcrr}
\hline Tout Day & Stock & N & Pr*AbnVol & St Dev & Percent \\
\hline No & Touted & 171 & $64.48^{*}$ & 53.45 & 0.37 \\
No & Control & 295 & $53.16^{*}$ & 56.52 & 0.63 \\
& Difference & & -11.31 & & \\
& T-stat & & -2.16 & & \\
Yes & & &. & & \\
Yes & Touted & 278 & $2.90^{*}$ & 4.30 & 0.74 \\
& Control & 96 & $4.38^{*}$ & 7.38 & 0.26 \\
& Difference & & 1.48 & & \\
\hline
\end{tabular}




\section{Table 3: "Group Level" Summary Statistics around Tout Days}

Table 3 presents "group-level" summary statistics on the variables in our sample around days on which there is a stock tout. A group is defined as a period of touting activity with no more than 5 consecutive days without a tout. The peak day is defined as the day within a group with the heaviest touting. "Beg - 1 to Peak" represents the period from the day before the beginning of the group of touts through the peak day of touting within each group. Peak day is the day within each group with the heaviest touting, and "Peak to End +2 " represents the period from the peak day of touting through two days after the touting within each group ends. $\mathrm{N}$ is the number of ticker-groups, MPR represents the average of the holding period midpoint return over the relevant period, and AbnVol is the average of abnormal volume across stocks, where abnormal volume is measured as a stock's daily dollar volume less its mean volume over the sample period, standardized by its mean volume. For the averages, ${ }^{*}$ denotes significance at the $\alpha=5 \%$ level. All data are from January 2004 - July, 2005.

Group Level Results

\begin{tabular}{lccccc}
\hline Stock & N & MPR & St Dev & AbnVol & St Dev \\
\hline Peak day & &. & & $\cdot$ & \\
Touted & 680 & 0.0014 & 0.1345 & $0.6453^{*}$ & 3.7001 \\
Control & 481 & 0.0038 & 0.0899 & -0.0532 & 1.8446 \\
Difference & & -0.0023 & & 0.6985 & \\
T-stat & & -0.36 & & 4.23 & \\
Beg-1 to Peak & &. & & & \\
Touted & 680 & $0.0083^{*}$ & 0.0821 & $0.4028^{*}$ & 2.1187 \\
Control & 495 & 0.0013 & 0.0563 & -0.0299 & 1.1573 \\
Difference & & 0.0070 & & 0.4327 & \\
T-stat & & 1.74 & & 4.49 & \\
Peak to End+2 & &. & &. & \\
Touted & 680 & -0.0085 & 0.0547 & $0.5206^{*}$ & 2.2672 \\
Control & 496 & 0.0021 & 0.0472 & 0.0682 & 1.7492 \\
Difference & & -0.0106 & & 0.4524 & \\
T-stat & & -3.55 & & 3.86 & \\
Beg-1 to End+2 & &. & &. & \\
Touted & 680 & -0.0031 & 0.0494 & $0.4410^{*}$ & 1.8693 \\
Control & 497 & 0.0016 & 0.0383 & 0.0429 & 1.3277 \\
Difference & & -0.0047 & & 0.3981 & \\
T-stat & & -1.84 & & 4.27 & \\
\hline
\end{tabular}




\section{Table 4: Impact of Touting on Returns \& Volume for Full Sample}

Table 4 gives results for a pooled cross-sectional, time-series generalized least squares regression for the entire sample period, 2004 only, and 2005 only, on all stocks in our sample. The left hand side of the table refers to the entire sample period, the middle panel gives results for observations from 2004, and the right hand side panel gives results for observations in 2005 only. Panel A uses midpoint return as the dependent variable and Panel B gives results using abnormal volume as the dependent variable. Abnormal volume is measured as a stock's daily dollar volume less its mean volume over the sample period, standardized by its mean volume. Int denotes intercept and tstk is a dummy variable that takes on the value 1 if the stock is touted and zero otherwise. \#touts is a variable that represents the number of touts on a given date, and cum5 is a variable that represents the cumulative effect of touting in the 5 days after touting occurs. Standard errors are adjusted for clustering. \# tickers gives the number of unique tickers used in each regression.

Panel A: Dependent Variable = Daily Return

\begin{tabular}{|c|c|c|c|c|c|c|c|c|c|c|c|}
\hline All & Est & Error & $\overline{P r}>\mid Z$ & 2004 & Est & Error & $\overline{P r}>\mid Z$ & 2005 & Est & Error & $\operatorname{Pr}>|Z|$ \\
\hline int & 0.0099 & 0.0011 & $<.0001$ & int & 0.0237 & 0.0056 & $<.0001$ & int & 0.0057 & 0.0041 & 0.1607 \\
\hline tstk & -0.0090 & 0.0077 & 0.2412 & tstk & -0.0166 & 0.0132 & 0.2094 & tstk & 0.0014 & 0.0015 & 0.3448 \\
\hline \#touts & 0.0010 & 0.0004 & 0.0093 & \#touts & 0.0014 & 0.0006 & 0.0136 & \#touts & 0.0003 & 0.0003 & 0.3663 \\
\hline cum5 & -0.0004 & 0.0001 & $<.0001$ & cum5 & -0.0004 & 0.0001 & $<.0001$ & cum5 & -0.0003 & 0.0001 & 0.0008 \\
\hline \# tickers & & & 798 & & & & 712 & & & & 628 \\
\hline
\end{tabular}

Panel B: Dependent Variable = Abnormal Volume

\begin{tabular}{lrrrrrrrrrrr}
\hline All & Est & Error & $\operatorname{Pr}>|Z|$ & $\mathbf{2 0 0 4}$ & Est & Error & $\operatorname{Pr}>|Z|$ & $\mathbf{2 0 0 5}$ & Est & Error & $\operatorname{Pr}>|Z|$ \\
\hline int & 0.8626 & 0.0034 & $<.0001$ & int & 0.5985 & 0.0180 & $<.0001$ & int & 0.5057 & 0.0857 & $<.0001$ \\
tstk & -0.0021 & 0.0243 & 0.9310 & tstk & -0.0071 & 0.0414 & 0.8631 & tstk & 0.0027 & 0.0140 & 0.8479 \\
\#touts & 0.0088 & 0.0042 & 0.0372 & \#touts & 0.0068 & 0.0061 & 0.2703 & \#touts & 0.0116 & 0.0048 & 0.0166 \\
cum5 & 0.0023 & 0.0010 & 0.0198 & cum5 & 0.0011 & 0.0014 & 0.4125 & cum5 & 0.0040 & 0.0013 & 0.0027 \\
\# tickers & & & 792 & & & & & 706 & & & \\
\hline
\end{tabular}




\section{Table 5: Impact of Touting on Returns \& Volume for Touted Stocks Only}

Table 5 gives results for a pooled cross-sectional, time-series generalized least squares regression for the entire sample period, 2004 only, and 2005 only, for touted stocks only. Results are presented in the left-hand-side, middle, and righthand side of the table, respectively. Panel A gives results using midpoint return as the dependent variable and Panel B gives results using abnormal volume as the dependent variable. Abnormal volume is measured as a stock's daily dollar volume less its mean volume over the sample period, standardized by its mean volume. Int denotes intercept, \#touts is a variable that represents the number of touts on a given date, and cum5 is a variable that represents the cumulative effect of touting in the 5 days after touting occurs. Standard errors are adjusted for clustering. \#tickers gives the number of unique stocks used in each regression.

Panel A: Dependent Variable = Daily Return

\begin{tabular}{|c|c|c|c|c|c|c|c|c|c|c|c|}
\hline All & Est & Error & $\overline{P r}>|Z|$ & 2004 & Est & Error & $\overline{P r}>|Z|$ & 2005 & Est & Error & $\overline{P r}>|Z|$ \\
\hline int & 0.0143 & 0.0000 & $<.0001$ & int & 0.0208 & 0.0000 & $<.0001$ & int & 0.0031 & 0.0044 & 0.4797 \\
\hline \#touts & 0.0009 & 0.0004 & 0.0220 & \#touts & 0.0012 & 0.0006 & 0.0349 & \#touts & 0.0003 & 0.0003 & 0.3421 \\
\hline cum5 & -0.0004 & 0.0001 & $<.0001$ & cum5 & -0.0004 & 0.0001 & $<.0001$ & cum5 & -0.0003 & 0.0001 & 0.0007 \\
\hline \# tickers & & & 289 & & & & 251 & & & & 269 \\
\hline
\end{tabular}

Panel B: Dependent Variable = Abnormal Volume

\begin{tabular}{|c|c|c|c|c|c|c|c|c|c|c|c|}
\hline All & Est & Error & $P r>\mid Z$ & 2004 & Est & Error & $\operatorname{Pr}>\mid Z$ & 2005 & Est & Error & $P r>\mid Z$ \\
\hline int & 0.3420 & 0.0000 & $<.0001$ & int & 0.5876 & 0.0001 & $<.0001$ & int & 0.4541 & 0.0667 & $<.0001$ \\
\hline \#touts & 0.0088 & 0.0043 & 0.0378 & \#touts & 0.0070 & 0.0062 & 0.2618 & \#touts & 0.0115 & 0.0048 & 0.0166 \\
\hline cum5 & 0.0024 & 0.0010 & 0.0130 & cum5 & 0.0015 & 0.0014 & 0.2660 & cum5 & 0.0037 & 0.0013 & 0.0046 \\
\hline \# tickers & & & 288 & & & & 250 & & & & 266 \\
\hline
\end{tabular}




\section{Table 6: Touting Activity Quintiles}

In Table 6, quintiles are formed based on daily touting activity. Quintile 5 (Quintile 1) represents the stock-days with the heaviest (lightest) amount of touting. Panel A gives the sample size for each quintile (based on stock-days), the average number of touts, average return, and average dollar value of trading activity (normal and abnormal) for each quintile. Values are calculated on tout days only. Vol is share volume, and AbnVol is abnormal share volume, measured as a stock's daily dollar volume less its mean volume over the sample period, standardized by its mean volume. Panel B presents "group-level" summary statistics on the variables in our sample for tickers in our sample that have the highest amount of touting activity around days that experience a tout. A group is defined as a period of touting during which there are no more than 5 days without a tout. $\mathrm{N}$ is the number of ticker-groups, Group Ret represents the holding period return (calculated from spread midpoints) over the relevant period. The peak day is defined as the day within a group with the heaviest touting. "Beg - 1 to Peak" represents the period from the day before the beginning of the group of touts through the peak day of touting within each group. Peak day is the day within each group with the heaviest touting, and "Peak to End +2 " represents the period from the peak day of touting through two days after the group of touts ends. In Panel $\mathrm{B}$, for the averages, ${ }^{*}$ denotes significance at the $\alpha=5 \%$ level. All data are from January, $2004-$ July, 2005.

Panel A: Summary Statistics by Quintile

\begin{tabular}{lrrrrr}
\hline Quintile & Stock-Days & Avg Touts & Ret & Pr*Vol & Pr*AbnVol \\
\hline 1 & 847 & 1.00 & -0.41 & $1,484.51$ & 110.79 \\
2 & 367 & 2.00 & 1.00 & $1,763.44$ & 308.89 \\
3 & 465 & 3.81 & -0.53 & $2,010.44$ & 404.68 \\
4 & 363 & 8.30 & 0.24 & $2,220.50$ & 503.65 \\
5 & 404 & 31.44 & 0.79 & $3,439.20$ & 651.63 \\
Diff Q5-Q1 & & & 1.20 & $1,954.69$ & 540.84 \\
T-stat & & 1.26 & 5.00 & 1.84 \\
\hline
\end{tabular}

Panel B: Quintile Group Level Results

\begin{tabular}{lccccc}
\hline Stock & N & Group Ret & St Dev & AbnVol & St Dev \\
\hline Peak day & &. & &. & \\
Touted & 306 & 0.0077 & 0.1505 & $0.3630^{*}$ & 1.5510 \\
Control & 481 & -0.0058 & 0.0784 & -0.1237 & 1.1029 \\
Difference & & 0.0135 & & 0.4867 & \\
T-stat & & 1.45 & & 4.77 & \\
Beg-1 to Peak & &. & &. & \\
Touted & 306 & 0.0296 & 0.2605 & $0.1863^{*}$ & 1.0783 \\
Control & 496 & -0.0046 & 0.1390 & -0.0368 & 1.2062 \\
Difference & & 0.0342 & & 0.2230 & \\
T-stat & & 2.12 & & 2.72 & \\
Peak to End+2 & &. & &. \\
Touted & 306 & -0.0619 & 0.2529 & $0.2813^{*}$ & 1.0032 \\
Control & 496 & 0.0142 & 0.5939 & -0.0084 & 0.9320 \\
Difference & & -0.0761 & & 0.2897 & \\
T-stat & & -2.51 & & 4.08 & \\
Beg-1 to End+2 & &. & &. & \\
Touted & 306 & -0.0454 & 0.2976 & $0.2335^{*}$ & 0.8976 \\
Control & 500 & 0.0151 & 0.6072 & 0.0005 & 0.8994 \\
Difference & & -0.0605 & & 0.2330 & \\
T-stat & & -1.89 & & & \\
\hline & & & & & \\
\hline
\end{tabular}




\section{Table 7: Industry Classifications}

Table 7 shows the distribution of the touted stocks in our sample across industries, as determined by 2-digit SIC code. The 2-digit SIC code is given in the leftmost column, the industry description is provided in the middle column, and the percentage of stocks in our sample that falls in the relevant industry is given in the rightmost column. The sample period is January, 2004 - July, 2005.

\begin{tabular}{|c|c|c|}
\hline SIC & Industry Description & Percent \\
\hline 73 & Business Services & $26.63 \%$ \\
\hline 48 & Communications & $7.05 \%$ \\
\hline 87 & Engineering, Accounting, Research, Management, And Related Services & $7.05 \%$ \\
\hline 28 & Chemicals And Allied Products & $6.27 \%$ \\
\hline 36 & Electronic And Other Electrical Equipment And Components, Except Computer Equipment & $5.48 \%$ \\
\hline 13 & Oil And Gas Extraction & $5.22 \%$ \\
\hline 20 & Food And Kindred Products & $4.18 \%$ \\
\hline 79 & Amusement And Recreation Services & $4.18 \%$ \\
\hline 80 & Health Services & $4.18 \%$ \\
\hline 10 & Metal Mining & $3.13 \%$ \\
\hline 38 & Measuring, Analyzing, And Controlling Instruments & $2.87 \%$ \\
\hline 35 & Industrial And Commercial Machinery And Computer Equipment & $2.35 \%$ \\
\hline 49 & Electric, Gas, And Sanitary Services & $2.09 \%$ \\
\hline 62 & Security And Commodity Brokers, Dealers, Exchanges, And Services & $2.09 \%$ \\
\hline 23 & Apparel And Other Finished Products Made From Fabrics And Similar Materials & $1.83 \%$ \\
\hline 39 & Miscellaneous Manufacturing Industries & $1.83 \%$ \\
\hline 14 & Mining And Quarrying Of Nonmetallic Minerals, Except Fuels & $1.31 \%$ \\
\hline 27 & Printing, Publishing, And Allied Industries & $1.31 \%$ \\
\hline 67 & Holding And Other Investment Offices & $1.31 \%$ \\
\hline 75 & Automotive Repair, Services, And Parking & $1.31 \%$ \\
\hline 29 & Petroleum Refining And Related Industries & $1.04 \%$ \\
\hline 37 & Transportation Equipment & $0.78 \%$ \\
\hline 65 & Real Estate & $0.78 \%$ \\
\hline 78 & Motion Pictures & $0.78 \%$ \\
\hline 15 & Building Construction General Contractors And Operative Builders & $0.52 \%$ \\
\hline 17 & Construction Special Trade Contractors & $0.52 \%$ \\
\hline 34 & Fabricated Metal Products, Except Machinery And Transportation Equipment & $0.52 \%$ \\
\hline 64 & Insurance Agents, Brokers, And Service & $0.52 \%$ \\
\hline 81 & Legal Services & $0.52 \%$ \\
\hline 82 & Educational Services & $0.52 \%$ \\
\hline 12 & Coal Mining & $0.26 \%$ \\
\hline 40 & Railroad Transportation & $0.26 \%$ \\
\hline 50 & Wholesale Trade-durable Goods & $0.26 \%$ \\
\hline 51 & Wholesale Trade-non-durable Goods & $0.26 \%$ \\
\hline 57 & Home Furniture, Furnishings, And Equipment Stores & $0.26 \%$ \\
\hline 60 & Depository Institutions & $0.26 \%$ \\
\hline 72 & Personal Services & $0.26 \%$ \\
\hline
\end{tabular}




\section{Table 8: Alternative Control Groups}

Table 8 presents summary statistics on the variables in our sample around days that experience a tout. Panel A refers to "group-level" results, with control firms from the smallest decile of NASDAQ stocks matched by 2-digit SIC industry code. Panel B refers to "group-level" results, with the control firms matched by price and abnormal volume, from the smallest decile of NASDAQ stocks. A group is defined as a period with fewer than 5 days without a tout. The peak day is defined as the day within a group with the heaviest touting. $\mathrm{N}$ is the number of ticker-groups, MPR represents the average daily return calculated from spread midpoints, and AbnVol is abnormal volume, measured as a stock's daily dollar volume less its mean volume over the sample period, standardized by its mean volume. "Beg - 1 to Peak" represents the period from the day before the beginning of the group of touts through the day of the tout. Peak day is the day of the heaviest touting, and "Peak to End +2 " represents the day of heaviest touting through the two days after the group of touts ends. For the means, ${ }^{*}$ denotes significance at the $\alpha=5 \%$ level. Our sample period is January, 2004 - July, 2005.

Panel A: NASDAQ Control Stocks Matched by 2 - Digit SIC Code

\begin{tabular}{lccccc}
\hline Stock & N & MPR & St Dev & AbnVol & St Dev \\
\hline Peak day & & $\cdot$ & & $\cdot$ & \\
Touted & 680 & 0.0014 & 0.1345 & 0.6453 & 3.7001 \\
Control & 536 & -0.0030 & 0.0385 & -0.1080 & 1.7339 \\
Difference & & 0.0044 & & 0.7533 & \\
T-stat & & 0.81 & & 4.70 & \\
Beg-1 to Peak & & $\cdot$ & & $\cdot$ & \\
Touted & 680 & $0.0083^{*}$ & 0.0821 & $0.4028^{*}$ & 2.3027 \\
Control & 549 & -0.0028 & 0.0279 & 0.0355 & 2.2378 \\
Difference & & 0.0112 & & 0.3673 & \\
T-stat & & 3.31 & & 2.93 & \\
Peak to End+2 & & $\cdot$ & & $\cdot$ & \\
Touted & 680 & -0.0085 & 0.0547 & $0.5206^{*}$ & 2.5622 \\
Control & 548 & 0.0004 & 0.0263 & 0.2109 & 4.0439 \\
Difference & & -0.0090 & & 0.3097 & \\
T-stat & & -3.77 & & 1.60 & \\
Beg-1 to End+2 & & $\cdot$ & &. & \\
Touted & 680 & -0.0031 & 0.0494 & $0.4410^{*}$ & 2.1423 \\
Control & 549 & -0.0004 & 0.0217 & 0.2038 & 3.2814 \\
Difference & & -0.0026 & & 0.2372 & \\
T-stat & & -1.25 & & 1.51 & \\
\hline
\end{tabular}

Panel B: NASDAQ Control Stocks Matched by Price and Abnormal Volume

\begin{tabular}{lrcccc}
\hline Stock & N & MPR & St Dev & AbnVol & St Dev \\
\hline Peak day & &. & & $\cdot$ & \\
Touted & 680 & 0.0014 & 0.1345 & 0.6453 & 3.7001 \\
Control & 91 & -0.0164 & 0.0844 & $2.0333^{*}$ & 9.3911 \\
Difference & & 0.0178 & & -1.3880 & \\
T-stat & & 1.74 & & -1.40 & \\
Beg-1 to Peak & &. & &. & \\
Touted & 680 & $0.0083^{*}$ & 0.0821 & $0.4028^{*}$ & 2.1187 \\
Control & 173 & -0.0056 & 0.0321 & 0.3586 & 3.5872 \\
Difference & & 0.0139 & & 0.0442 & \\
T-stat & & 3.49 & & 0.16 & \\
Peak to End+2 & &. & &. & \\
Touted & 680 & -0.0085 & 0.0547 & $0.5206^{*}$ & 2.2672 \\
Control & 260 & $0.0071^{*}$ & 0.0481 & $1.0302^{*}$ & 3.8657 \\
Difference & & -0.0156 & & -0.5095 & \\
T-stat & & -4.29 & & -2.00 & \\
Beg-1 to End+2 & &. & &. \\
Touted & 680 & -0.0031 & 0.0494 & $0.4410^{*}$ & 1.8693 \\
Control & 260 & $0.0045^{*}$ & 0.0341 & $0.8798^{*}$ & 3.2731 \\
Difference & & -0.0076 & & -0.4388 & \\
T-stat & & -2.66 & & -2.04 & \\
\hline
\end{tabular}




\section{Table 9: Touting Strategy}

Table 9 presents summary statistics on returns and volume to a strategy that takes advantage of the most effective touting strategy. Results are at the "group-level." Control stocks are determined in the same way as in Table 1. A group is defined as a period with fewer than 5 days without a tout. The peak day is defined as the day within a group with the heaviest touting. "Beg - 1 to Peak" represents the period from the day before the beginning of the group of touts through the day of the tout. Peak day is the day of the heaviest touting, and "Peak to End +2 " represents day of heaviest touting through the two days after the group of touts ends. $\mathrm{N}$ is the number of ticker-groups, HPR represents the average return for the group-level results, and is calculated by buying and selling at the closing price on the specified days. AbnVol is abnormal volume, measured as a stock's daily dollar volume less its mean volume over the sample period, standardized by its mean volume. In the lower sub-panel of the table, we present the hypothetical profit (in dollars) to a spammer who invests $\$ 1000$ in each touted stock on the day before the peak day of touting and liquidates his position on the peak day of touting, assuming round-trip transaction costs ranging from 0 to 100 basis points. Our sample period is January, 2004 - July, 2005.

\begin{tabular}{|c|c|c|c|c|c|c|c|}
\hline Stock & $\mathbf{N}$ & HPR & StDev & AbnVol & StDev & \% Spread & StDev \\
\hline \multicolumn{8}{|l|}{ Peak day } \\
\hline Touted & 420 & 0.0030 & 0.1400 & 0.8278 & 4.3115 & 0.1335 & 0.1683 \\
\hline Control & 297 & 0.0077 & 0.0934 & -0.0173 & 1.9845 & 0.2642 & 0.3188 \\
\hline Difference & & -0.0047 & & 0.8451 & & -0.1308 & \\
\hline T-stat & & -0.54 & & 3.52 & & -6.46 & \\
\hline \multicolumn{8}{|l|}{ Beg-1 to Peak } \\
\hline Touted & 420 & 0.0429 & 0.2741 & 0.4898 & 2.4548 & 0.1381 & 0.1497 \\
\hline Control & 305 & 0.0063 & 0.1439 & -0.0160 & 1.1958 & 0.2574 & 0.3098 \\
\hline Difference & & 0.0366 & & 0.5058 & & -0.1193 & \\
\hline T-stat & & 2.33 & & 3.67 & & -6.22 & \\
\hline \multicolumn{8}{|l|}{ Peak to End +2} \\
\hline Touted & 420 & -0.0537 & 0.2482 & 0.6266 & 2.6578 & 0.1327 & 0.1389 \\
\hline Control & 306 & 0.0132 & 0.2491 & 0.0475 & 1.9771 & 0.2587 & 0.3166 \\
\hline Difference & & -0.0669 & & 0.5791 & & -0.1260 & \\
\hline T-stat & & -3.58 & & 3.37 & & -6.52 & \\
\hline \multicolumn{8}{|l|}{ Beg-1 to End+2 } \\
\hline Touted & 420 & -0.0203 & 0.3179 & 0.5233 & 2.1987 & 0.1344 & 0.1340 \\
\hline Control & 306 & 0.0112 & 0.2640 & 0.0315 & 1.4807 & 0.2582 & 0.3132 \\
\hline Difference & & -0.0315 & & 0.4918 & & -0.1238 & \\
\hline T-stat & & -1.46 & & 3.60 & & -6.50 & \\
\hline One-Way Cost & $\overline{0}$ & $\overline{1}$ & $\overline{2}$ & $\overline{3}$ & $\overline{44}$ & $\overline{\overline{5}}$ & $\overline{\overline{50}}$ \\
\hline Profit & 18018.00 & 17932.20 & 17846.40 & 17760.59 & 17674.79 & 17588.99 & 13727.91 \\
\hline
\end{tabular}




\section{Figure 1: Spam E-mail Touting Stock}

Figure 1 gives an example of spam e-mail touting a stock (CWTD).

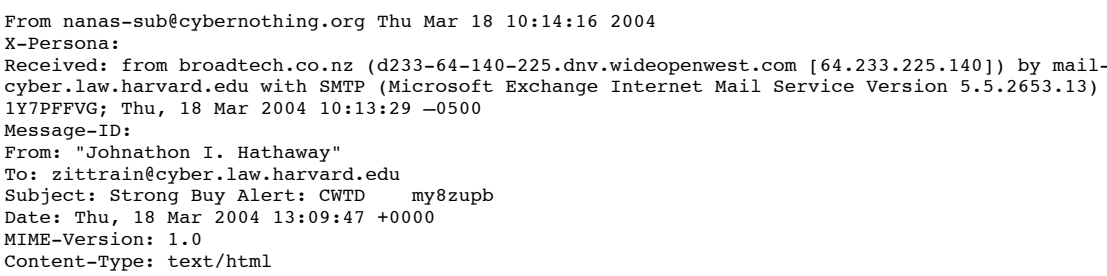

\section{Financial Insiders Report}

Mid-Week Report

If you loved your 900 percent gains on our stock pick last week, we think our next pick, China World Trade Corp. "CWTD" will do even better!!

Strong-Buy Alert !

*Breaking News in the Previous 2 weeks*

CWTD Makes Application to list on Amex

China World Trade Corp Signs Letter of Intent to Acquire Controlling Stake of Guangdong Huahao Industries Holdings Limited

China World Trade Corp. ticker: "CWTD"

CHINA WORLD TRADE CORP.

Symbol: CWTD OTC.BB

Price $\$ 4.80<$ THIS WAS PROFILED AT 1.502 WEEKS AGO>

Shares out: 16Million

Market Capitalization: \$ 19Million

Significant Revenue Growth in 2004

Average PE Industry: $30 x$

Rating: Strong Buy

7 days trading target: $\$ 6.50$

30 day trading target: $\$ 7.50$

Investment Outlook

- CWTD HAS A STRONG MANAGEMENT TEAM THAT INCLUDES TOP LOCAL CORPORATE OFFICERS, HIGH RANKING SENIOR GOVERNMENT OFFICIALS AND SENIOR MANAGEMENT FROM THE HONG KONG WORLD TRADE CENTER

IN THE LAST TWENTY YEARS, THE FOREIGN DIRECT INVESTMENT INTO CHINA HAS INCREASED FROM 0.92 BILLION USD IN 1983 TO 52.74 BILLION USD IN 2004

- CWTD IS FIRMLY POSITIONED TO VASTLY EXPAND ITS MARKETING AND ACOUISITION STRATEGIES AND CAPITALIZE ON ASIA'S MULTI-BILLION DOLLAR EMERGING MARKET.

- CWTD HAS JUST MADE THE APPLICATION TO LIST ON THE AMEX!!!

- CHINA WORLD TRADE CORP SIGNS LETTER OF INTENT TO ACQUIRE CONTROLLING STAKE OF GUANGDONG HUAHAO INDUSTRIES HOLDINGS LIMITED

CWTD is our PLAY OF THE MONTH stock pick.

Here are a few simple reasons why one would own China World Trade Corp:

- China World Trade Corporation is an official operator of World Trade Centers in China, in association with The World Trade Centers Association (WTCA) and offers an enormous variety of services for businesses and industries seeking to do business in China.

- The Company's business model consists of three major components -- The World Trade Center business, value-added services, and strategic investments.

- China World Trade Corporation established the first World Trade Center in the province of Guangzhou (Canton) in the year 2002 and started the commercial operation at the beginning of 2003. This significant event was covered in detail on CNN ASIA.

- With the recent tragic events of 9-11, the name World Trade Center has instant global recognition, and stands for unity, strength and prosperity throughout the worlds top economy leaders.

- China World Trade Corp Signs Letter of Intent to Acquire Controlling Stake of Guangdong Huahao Industries Holdings Limited

- China World Trade Corp Signs Letter of Intent to Acquire Controlling Stake of Guangdong Huahao
CWTD's business potential is built upon the opportunity created by the international trade of China.

Don't be sorry next week that you forgot to buy this one!

China World Trade Corp. is uniquely positioned and capitalizing on the rapidly expanding asian markets!

Investors take note, Get in early !

Information within this email contains "forward looking statements" within the meaning of Section $27 \mathrm{~A}$ of the Securities Act of 1933 and Section $21 \mathrm{~B}$ of the Securities Exchange Act of
1934. Any statements that express or involve discussions with respect to predictions, goals, expectations, beliefs, plans, projections, bejectives, assumptions of future events or 1934. Any statements that express or involve discussions with respect to predictions, goals, expectations, beliefs, plans, projections, objectives, assumptions or future events or

Forward looking statements are based on expectations, estimates and projections at the time the statements are made that involve a number of risks and uncertainties which could cause actual results or events to differ materially from those presently anticipated. Forward looking statements in this action may be identified through the use of words such as: "projects", subscribers to seek advice from a registered professional securities representative before deciding to trade in stocks featured within this email. None of the material within this report shall be construed as any kind of investment advice. GS Research and/or its officers and employees have been compensated 50,000 open trade shares by a third party for work involved in the preparang

In compliance with Section 17(b), we disclose the holding of independently purchased shares of the company mentioned prior to the publication of this report. Be aware of an inheren made regarding the above company. Short term trading targets are only guesses on our 3 fat) Keep in mind that when trading small stocks like the company above there is a chance for entertie ent peny you 


\section{Figure 2: Returns to Touted and Control Stocks}

Figure 2 plots average daily returns and cumulative returns for Touted and Control stocks in an 11 day window around a stock tout (where day 0 marks the event day when a stock is touted). Returns are calculated from daily closing prices. Event days are plotted on the $\mathrm{X}$-axis and returns (in decimals) are given on the Y-axis. Touted stocks in our sample are stocks for which a tout e-mail is reported in our database. On each event day, one control stock for which there are no reported touts during our sample period is picked at random out of an already randomly selected group of Pink Sheets stocks. The sample period is January, 2004 - July, 2005.

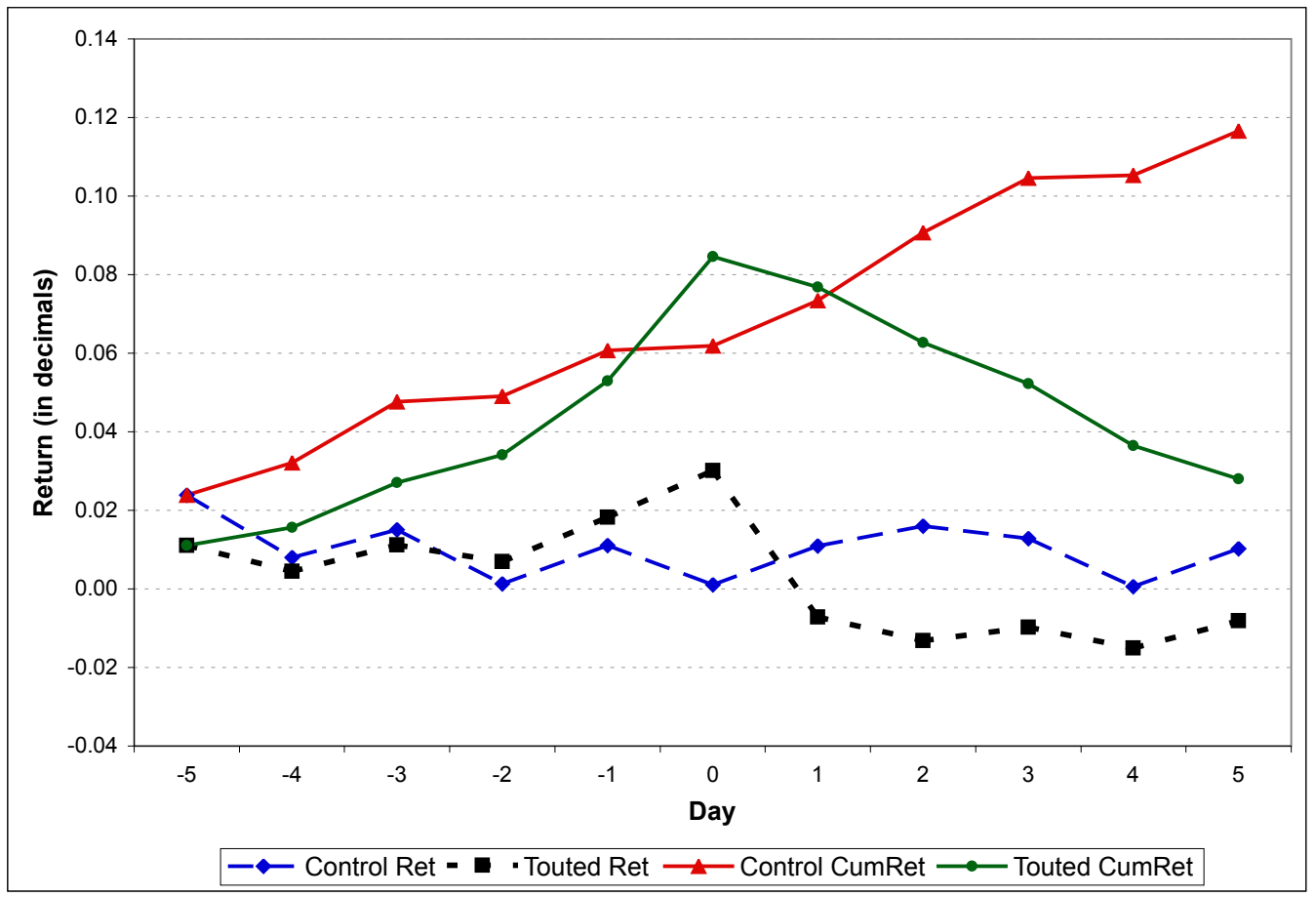




\section{Figure 3: Abnormal Volume of Trading in Touted and Control Stocks}

Figure 3 plots average daily abnormal volume and cumulative abnormal volume for Touted and Control stocks in an 11 day window around a stock tout (where day 0 marks the event day when a stock is touted). Abnormal volume is measured as a stock's daily dollar volume less its mean volume (over the sample period) standardized by its mean volume. Event days are plotted on the $\mathrm{X}$-axis and abnormal dollar volume is given on the $\mathrm{Y}$-axis. Touted stocks in our sample are stocks for which a tout e-mail is reported in our database. On each event day, one control stock for which there are no reported touts during our sample period is picked at random out of an already randomly selected group of Pink Sheets stocks. The sample period is January, 2004 - July, 2005.

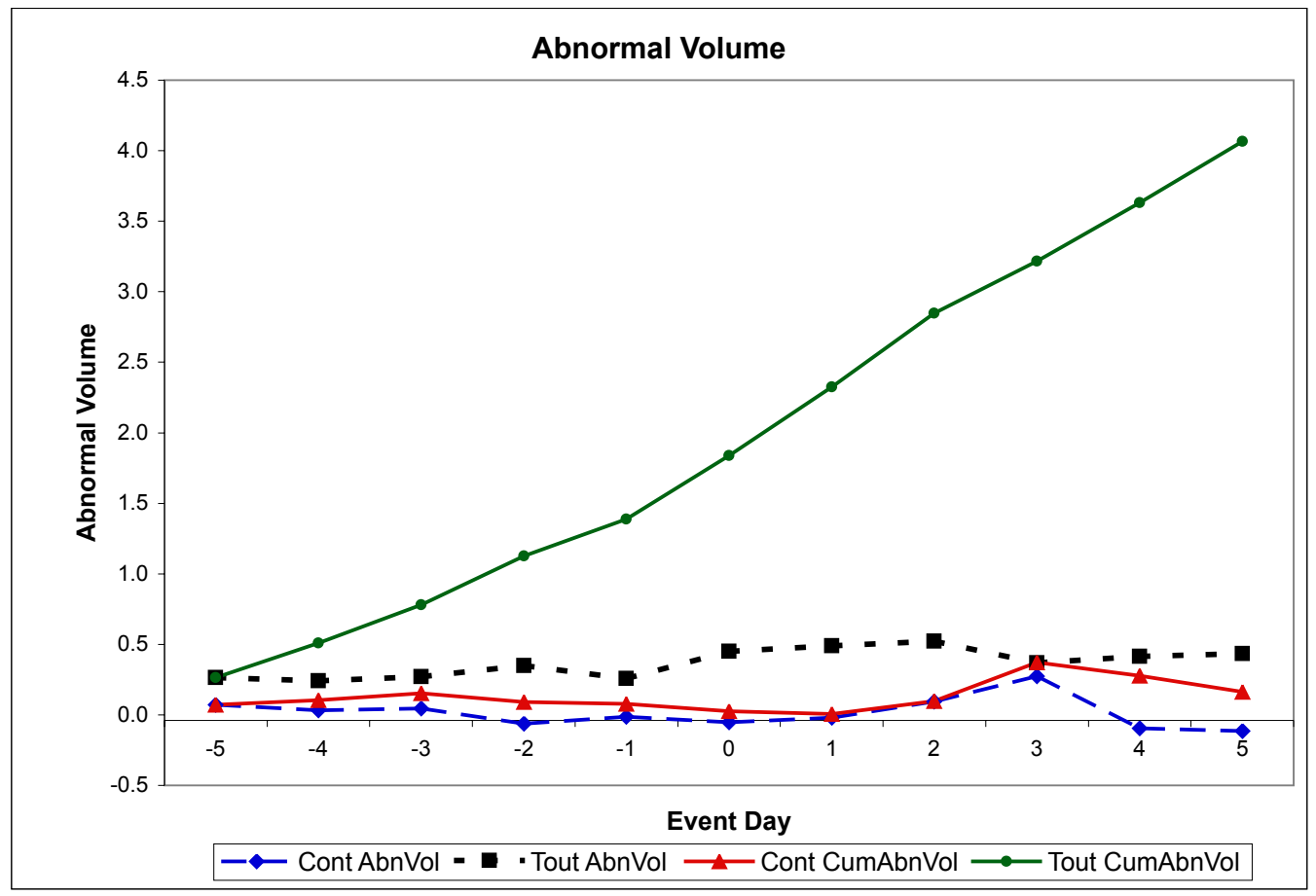




\section{Figure 4: Trading Activity for Touted Stocks Grouped by Tout Volume}

Figure 4 plots average daily trading activity and average daily abnormal trading activity for stocks in each touting activity quintile. Quintiles are determined by ranking stock-days by touting activity. Quintile 5 (Quintile 1) has the most (least) touting activity. The quintile is given on the X-axis. Average dollar value of trading activity (Left Y-Axis) is determined by price multiplied by share volume. Average dollar value of abnormal trading activity (Right Y-Axis) is determined by price multiplied by abnormal volume, where abnormal volume is measured as a stock's daily dollar volume less its mean volume (over the sample period) standardized by its mean volume. The sample period is January, 2004 - July, 2005.

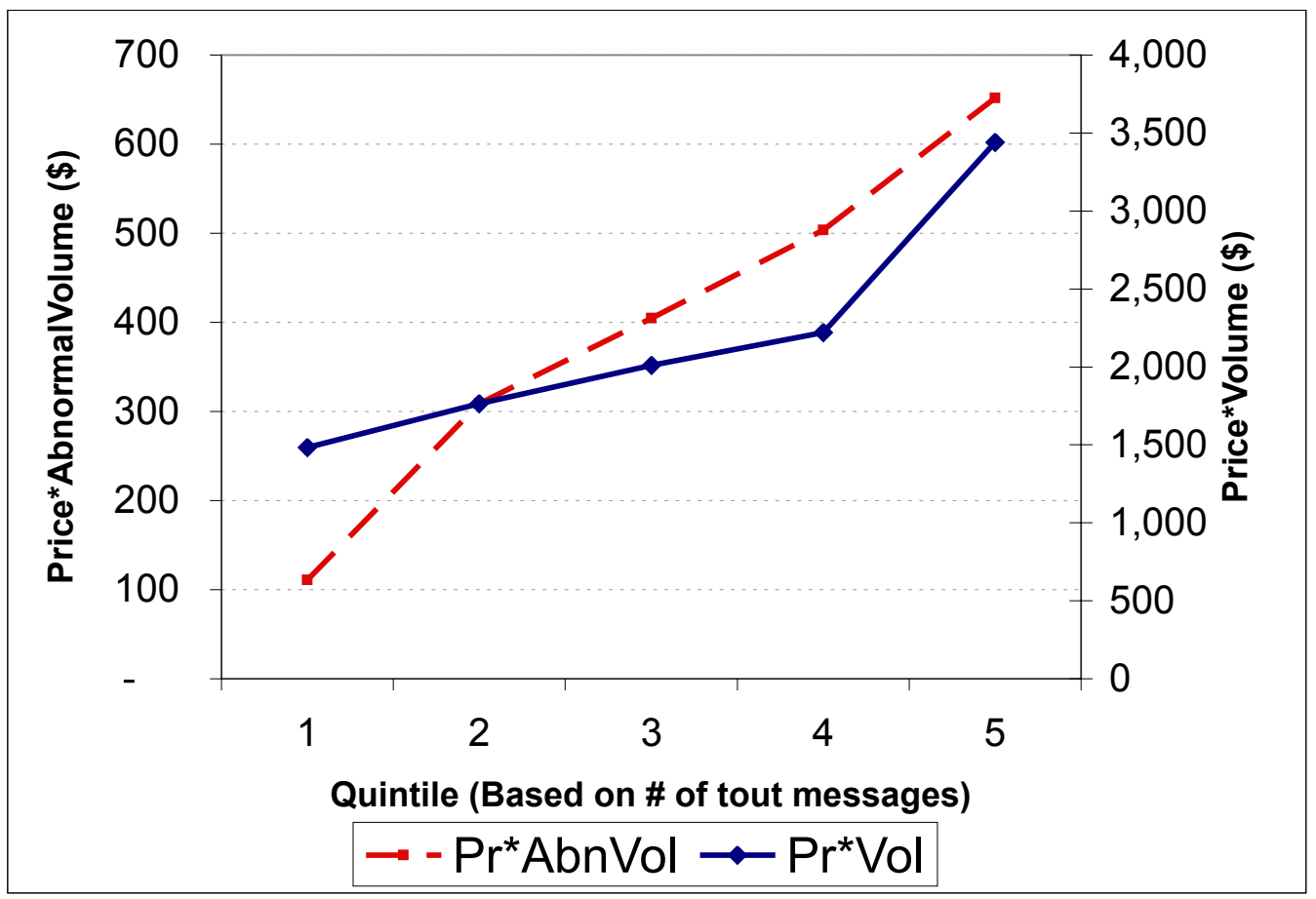

